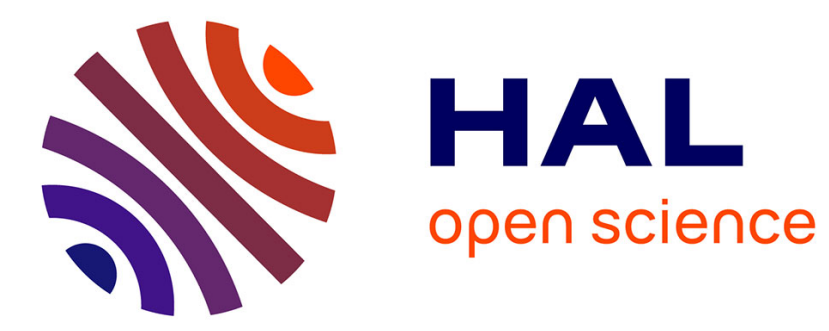

\title{
3-D velocity structure in southern Haiti from local earthquake tomography
}

R. Douilly, William L. Ellsworth, E. Kissling, Andrew M. Freed, Anne

Deschamps, B. Mercier de Lépinay

\section{- To cite this version:}

R. Douilly, William L. Ellsworth, E. Kissling, Andrew M. Freed, Anne Deschamps, et al.. 3-D velocity structure in southern Haiti from local earthquake tomography. Journal of Geophysical Research: Solid Earth, 2016, 121 (12), pp.8813 - 8832. 10.1002/2016JB013123 . hal-01527925

\section{HAL Id: hal-01527925 \\ https://hal.science/hal-01527925}

Submitted on 13 Dec 2021

HAL is a multi-disciplinary open access archive for the deposit and dissemination of scientific research documents, whether they are published or not. The documents may come from teaching and research institutions in France or abroad, or from public or private research centers.
L'archive ouverte pluridisciplinaire HAL, est destinée au dépôt et à la diffusion de documents scientifiques de niveau recherche, publiés ou non, émanant des établissements d'enseignement et de recherche français ou étrangers, des laboratoires publics ou privés.

$$
\text { Copyright }
$$




\section{Journal of Geophysical Research: Solid Earth}

\section{RESEARCH ARTICLE}

10.1002/2016JB013123

Key Points:

- Local tomography in Haiti

- 3-D P and $S$ velocity inversions

- Aftershock relocations

Supporting Information:

- Supporting Information S1

- Table S1

Correspondence to:

R. Douilly,

roby.douilly@ucr.edu

\section{Citation:}

Douilly, R., W. L. Ellsworth, E. Kissling,

A. M. Freed, A. Deschamps, and

B. Mercier de Lépinay (2016), 3-D

velocity structure in southern Haiti

from local earthquake tomography,

J. Geophys. Res. Solid Earth, 121,

8813-8832, doi:10.1002/2016JB013123.

Received 25 APR 2016

Accepted 25 NOV 2016

Accepted article online 6 DEC 2016

Published online 20 DEC 2016

(c2016. American Geophysical Union All Rights Reserved.

\section{3-D velocity structure in southern Haiti from local earthquake tomography}

\author{
Roby Douilly ${ }^{1,2} \mathbb{D}$, William L. Ellsworth ${ }^{3}$ (D) Edi Kissling ${ }^{4}$, Andrew M. Freed', \\ Anne Deschamps ${ }^{5}$, and Bernard Mercier de Lépinay ${ }^{5}$ \\ ${ }^{1}$ Department of Earth, Atmospheric and Planetary Sciences, Purdue University, West Lafayette, Indiana, USA, ${ }^{2}$ Department \\ of Earth Sciences, University of California, Riverside, California, USA, ${ }^{3}$ Department of Geophysics, Stanford University, \\ Stanford, California, USA, ${ }^{4}$ Institute of Geophysics, ETH Zurich, Zurich, Switzerland, ${ }^{5}$ Géoazur, Université Nice Sophia \\ Antipolis, Nice, France
}

Abstract We investigate 3-D local earthquake tomography for high-quality travel time arrivals from aftershocks following the 2010 M7.0 Haiti earthquake on the Léogâne fault. The data were recorded by 35 stations, including 19 ocean bottom seismometers, from which we selected 595 events to simultaneously invert for hypocenter location and 3-D $V_{p}$ and $V_{s}$ velocity structures in southern Haiti. We performed several resolution tests and concluded that clear features can be recovered to a depth of $15 \mathrm{~km}$. At $5 \mathrm{~km}$ depth we distinguish a broad low-velocity zone in the $V_{p}$ and $V_{s}$ structure offshore near Gonave Island, which correlate with layers of marine sediments. Results show a pronounced low-velocity zone in the upper $5 \mathrm{~km}$ across the city of Léogâne, which is consistent with the sedimentary basin location from geologic map. At $10 \mathrm{~km}$ depth, we detect a low-velocity anomaly offshore near the Trois Baies fault and a NW-SE directed low-velocity zone onshore across Petit-Goâve and Jacmel, which is consistent with a suspected fault from a previous study and that we refer to it in our study as the Petit-Goâve-Jacmel fault. These observations suggest that low-velocity structures delineate fault structures and the sedimentary basins across the southern peninsula, which is extremely useful for seismic hazard assessment in Haiti.

\section{Introduction}

The 2010 M7.0 Haiti earthquake ruptured the multisegment Léogâne fault [Douilly et al., 2013, 2015; Meng et al., 2012; Symithe et al., 2013], killed about 240,000 people, and caused heavy damage in the Port-au-Prince region equivalent to the country's annual gross national product [Bellerive, 2010]. As tragic as this event was, data collected during this event and its associated aftershocks provide useful insight to better understand the tectonics of this region. This event was originally thought to have happened on the Enriquillo Plantain Garden Fault (EPGF), the main active fault running through the southern peninsula (Figure 1), based on historical seismic activity and geodetic measurements showing significant strain buildup on this fault [Manaker et al., 2008]. However, results of post-event investigations revealed that the 2010 earthquake occurred on the previously unknown Léogâne fault just a few kilometers from the Enriquillo Fault [Calais et al., 2010; Douilly et al., 2013].

GPS measurements constraining block models suggest that the EPGF, which previously ruptured more than 250 years ago, has accommodated sufficient strain in that time period to generate a $M 7.2$ earthquake if all of that strain was released in one event [Calais et al., 2010; Manaker et al., 2008]. The 2010 rupture only released a fraction of this strain buildup, which combined with the lack of large earthquakes in the past two centuries suggests that the potential for additional activity remains high. A significant number of aftershocks occurred on the offshore reverse Trois Baies fault (TBF), triggered by an increase in coseismic Coulomb stress change [Symithe et al., 2013]. This raises possibility that the Trois Baies and the Léogâne faults are representative of previously unrecognized active faults. Recently, Saint Fleur et al. [2015] mapped a south dipping thrust fault that they referred to as the Lamentin fault. This fault runs offshore at the Canal-du-Sud and continues onshore to connect to the EPGF. This raises the question of whether there might be other unknown, potentially active faults in the region.

Douilly et al. [2013] developed a 1-D velocity model of southern Haiti, from the joint inversion of $P$ and $S$ arrival times from aftershocks of the earthquake. Large, positive $P$ and $S$ station corrections (i.e., observed travel times are slow) were observed for their deepest Ocean Bottom Seismometer stations offshore. They inferred 


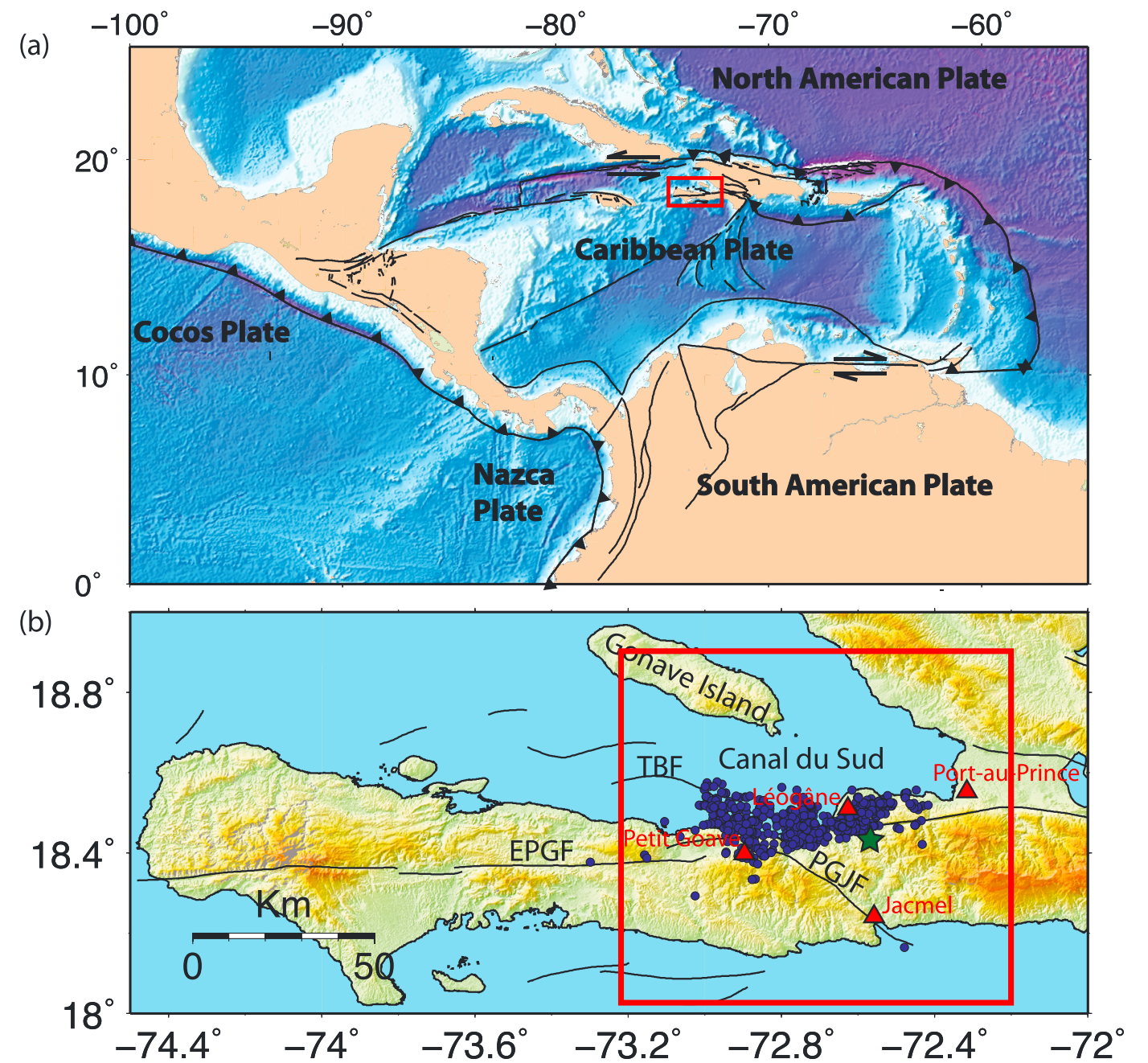

Figure 1. (a) Tectonic settings of the Caribbean plate with respect to the surrounding plate boundaries. The island of Hispaniola lies at the boundary between the Caribbean plate and the North American plate. (b) Enlarged view of the southern peninsula of Haiti. The red triangles show the location of urban cities. The black lines represent the fault traces. Enriquillo Plantain Garden fault, EPGF; Trois Baies fault, TBF; Petit-Goâve-Jacmel fault, PGJF. The green star shows the location of the 2010 Haiti earthquake according to the NEIC. The blue circles show the relocated subset of aftershocks from this tomography study. The red rectangle in Figure 1a shows the area covered on Figure 1b.

that the delays were caused by thick sedimentary layers, providing clear evidence for lateral variation in velocity. A change in velocity can be caused by several possibilities. Tomographic studies have shown that high-velocity anomalies are sometimes associated with seismic activity, with more brittle and competent rock in the crust with the ability to sustain seismogenic stress and release it in seismic events [Lees and Nicholson, 1993; Scott et al., 1994; Zhao and Kanamori, 1995]. Low-velocity zones within the crust have also been associated with known faults, presumably because of the fractured nature of the crust [Eberhart-Phillips and Bannister, 2002; Eberhart-Phillips and Reyners, 1997; Lees, 1990]. And other factors such as compositional variations, high fluid pressure [Zhao and Kanamori, 1995], or the presence of sedimentary basin [Baher and Davis, 2003] have also been associated with the presence of low-velocity zones.

Here we develop a three-dimensional $V_{p}$ and $V_{s}$ structure of southern Haiti by using arrival times for aftershock of the 2010 earthquake in order to understand the 3-D seismic structure and investigate the cause for observed velocity heterogeneities. We seek to address whether low-velocity regions can be correlated with the known or unmapped faults in southern Haiti, whether a tomography study can outline some differences in the internal structure of the Southern Peninsula and whether it can delineate the extent of the thick sedimentary layer offshore near the Canal-du-Sud [Momplaisir, 1986] or onshore near the city of Léogâne. 


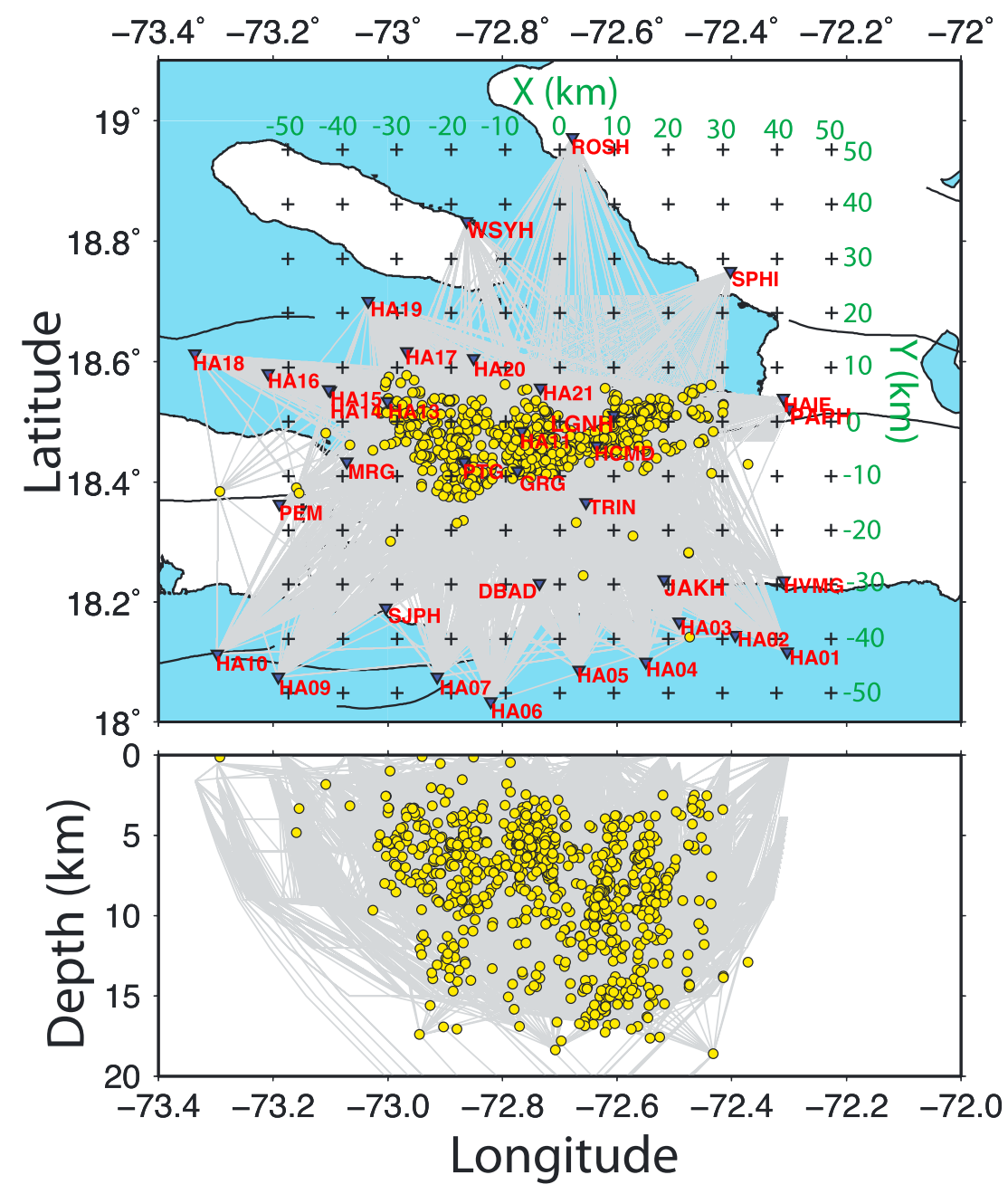

Figure 2. Map view and the E-W cross section of the aftershocks selected for this study. The inverted triangles show the seismic station distribution, and the plus sign represent the horizontal $10 \times 10 \mathrm{~km}$ grid size used for the 3-D inversion. The grey lines on the map view and cross section represent the ray coverage from the minimum 1-D model between the 595 events and the stations that were used to locate them.

\section{Data Selection and Inversion Method}

Temporary network seismic stations, installed after the January 2010 earthquake, recorded 1200 aftershocks between February and June [Mercier de Lépinay et al., 2011; Douilly et al., 2013] . The network was composed of 35 short-period and broadband stations (Figure 2) with a non-uniform time deployment (Table 1). $P$ wave $(13,503)$ and $S$ wave $(10,190)$ arrivals were handpicked by using the Seismic Analysis Code [Goldstein et al., 2003]. Douilly et al. [2013] used this data set to determine a 1-D regional crustal velocities, to relocate all events using VELEST [Kissling et al., 1994, 1995], and further improved the locations by using a double difference algorithm [Waldhauser and Ellsworth, 2000]. However, the depth distribution from this velocity model was not optimal for carrying out a 3-D tomography study with a depth increment of $5 \mathrm{~km}$, consistent with the density of the raypath distribution. Thus, we begin the present study by re-parameterizing the 1-D velocity model in order for the depth profile such that the Minimum 1-D model is a close approximations of the initial 3-D model [Kissling, 1988].

\subsection{Minimum 1-D Velocity Model}

In order to insure a stable 3-D inversion, a high-quality subset of events with at least six $P$ and six $S$ arrivals and with an azimuthal gap less than $180^{\circ}$ was extracted from the seismic arrival times from Douilly et al. [2013]. We used the program VELEST [Kissling et al., 1995] to invert for velocity, station correction, and hypocenter 
Table 1. Seismic Station Information With Their Delay Time Corrections Determined Jointly With the 1-D Velocity Model

\begin{tabular}{|c|c|c|c|c|c|c|c|c|}
\hline Station Name & Latitude $\left({ }^{\circ} \mathrm{N}\right)$ & Longitude ( $\left.{ }^{\circ} \mathrm{W}\right)$ & Elevation (km) & $\begin{array}{c}P \text { Wave Station } \\
\text { Correction }(\mathrm{s})\end{array}$ & $\begin{array}{c}\text { S Wave Station } \\
\text { Correction (s) }\end{array}$ & $\begin{array}{c}\text { Date } \\
\text { Installed }\end{array}$ & $\begin{array}{c}\text { Date } \\
\text { Recovered }\end{array}$ & Network Name \\
\hline DBAD & 18.2315 & 72.73536 & 0.534 & 0.08 & 0.47 & 15/3/10 & $25 / 6 / 10$ & USGS \\
\hline HCMD & 18.4606 & 72.65593 & 0.074 & 0.00 & 0.00 & 13/3/10 & $25 / 6 / 10$ & \\
\hline HVMG & 18.2357 & 72.30294 & 0.145 & -0.34 & -0.29 & $16 / 3 / 10$ & $24 / 6 / 10$ & \\
\hline ROSH & 18.9725 & 72.67772 & 0.139 & -0.55 & -0.69 & $9 / 3 / 10$ & $24 / 6 / 10$ & \\
\hline SJPH & 18.1903 & 73.00340 & 0.022 & 0.09 & 0.54 & $16 / 3 / 10$ & $22 / 6 / 10$ & \\
\hline SPHI & 18.7501 & 72.40264 & 0.101 & -0.34 & -0.30 & $11 / 3 / 10$ & $22 / 6 / 10$ & \\
\hline TRIN & 18.3662 & 72.65462 & 0.334 & 0.11 & 0.63 & $17 / 3 / 10$ & $25 / 6 / 10$ & \\
\hline WSYH & 18.833 & 72.86274 & 0.029 & -0.44 & -0.54 & $10 / 3 / 10$ & & \\
\hline JAKH & 18.2377 & 72.5180 & 0.047 & 0.11 & 0.65 & $16 / 2 / 10$ & & NRCAN \\
\hline LGNH & 18.5110 & 72.6058 & 0.062 & -0.09 & 0.18 & $14 / 2 / 10$ & & \\
\hline PAPH & 18.5225 & 72.2993 & 0.218 & -0.08 & 0.28 & $11 / 2 / 10$ & & \\
\hline PEM & 18.3627 & 73.1888 & 0.29 & -0.03 & 0.30 & $10 / 2 / 10$ & $15 / 5 / 10$ & IPGP \\
\hline MRG & 18.4335 & 73.0712 & 0.05 & -0.05 & 0.23 & $10 / 2 / 10$ & $15 / 5 / 10$ & \\
\hline PTG & 18.4338 & 72.8668 & 0.01 & 0.05 & 0.58 & $10 / 2 / 10$ & $15 / 5 / 10$ & \\
\hline GRG & 18.4182 & 72.7738 & 0.04 & 0.08 & 0.49 & $10 / 2 / 10$ & $15 / 5 / 10$ & \\
\hline HAIF & 18.5395 & 72.3097 & 0.15 & -0.06 & 0.33 & $10 / 2 / 10$ & $15 / 5 / 10$ & Sismo-Ecole \\
\hline HA01 & 18.1167 & 72.3037 & -3.85 & -0.16 & 0.56 & $10 / 2 / 10$ & $15 / 5 / 10$ & GEOAZUR (BBOBS) \\
\hline HA05 & 18.0503 & 72.6663 & -1.98 & 0.20 & 1.16 & $10 / 2 / 10$ & $15 / 5 / 10$ & \\
\hline HA11 & 18.4843 & 72.766 & -1.09 & -0.07 & 0.71 & $10 / 2 / 10$ & $15 / 5 / 10$ & \\
\hline HA14 & 18.5538 & 73.1033 & -1.55 & 0.55 & 1.74 & $10 / 2 / 10$ & $15 / 5 / 10$ & \\
\hline HA17 & 18.6167 & 72.9672 & -1.51 & -0.03 & 1.04 & $10 / 2 / 10$ & $15 / 5 / 10$ & \\
\hline HAO2 & 18.145 & 72.3938 & -2.71 & -0.12 & 1.02 & $10 / 2 / 10$ & $9 / 3 / 10$ & IFREMER (microOBS) \\
\hline HA03 & 18.1667 & 72.4917 & -0.46 & -0.04 & 0.67 & $10 / 2 / 10$ & $9 / 3 / 10$ & \\
\hline HAO4 & 18.1 & 72.5498 & -2.4 & 0.20 & 1.12 & $10 / 2 / 10$ & $9 / 3 / 10$ & \\
\hline HA06 & 18.0337 & 72.8203 & -1.64 & 0.27 & 1.09 & $10 / 2 / 10$ & $9 / 3 / 10$ & \\
\hline HA07 & 18.0752 & 72.9135 & -1.13 & 0.21 & 0.98 & $10 / 2 / 10$ & $9 / 3 / 10$ & \\
\hline HA09 & 18.0747 & 73.191 & -1.16 & -0.03 & 0.67 & $10 / 2 / 10$ & $9 / 3 / 10$ & \\
\hline HA10 & 18.1137 & 73.297 & -1.43 & 0.04 & 0.87 & $10 / 2 / 10$ & $9 / 3 / 10$ & \\
\hline HA13 & 18.5338 & 73.0002 & -1.65 & 0.22 & 1.33 & $10 / 2 / 10$ & $9 / 3 / 10$ & \\
\hline HA15 & 18.5517 & 73.1008 & -1.55 & 0.32 & 1.56 & $10 / 2 / 10$ & $9 / 3 / 10$ & \\
\hline HA16 & 18.58 & 73.2082 & -1.31 & 0.17 & 1.53 & $10 / 2 / 10$ & $9 / 3 / 10$ & \\
\hline HA18 & 18.6132 & 73.3367 & -1.59 & 0.21 & 1.18 & $10 / 2 / 10$ & $9 / 3 / 10$ & \\
\hline HA19 & 18.7003 & 73.0337 & -1.04 & -0.18 & 0.43 & $10 / 2 / 10$ & $9 / 3 / 10$ & \\
\hline HA2O & 18.6052 & 72.8507 & -0.83 & 0.05 & 0.77 & $10 / 2 / 10$ & $9 / 3 / 10$ & \\
\hline HA21 & 18.5565 & 72.7335 & -0.67 & -0.01 & 0.72 & $10 / 2 / 10$ & $9 / 3 / 10$ & \\
\hline
\end{tabular}

location by minimizing the travel time residual [Crosson, 1976; Kissling et al., 1994, 1995]. For inversion of travel times, each observation provides one equation to the system, and each equation is weighted in relation to the individual uncertainty normalized with respect to the top quality. Top quality of our data/equations is defined by error for class 0 , i.e., $0.02 \mathrm{~s}$. Class 1 is attributed double this error and, hence, acquires half the weight of that of class 0 , i.e., $50 \%$. Consequently, for the data set at hand, class 2 is attributed a weight of $33 \%$ and class 3 a weight of $25 \%$. At present in VELEST, class 2 observations are attributed only $25 \%$ rather than the $33 \%$ they would deserve and class 3 observations are attributed only $12.5 \%$ rather than the $25 \%$ they would deserve. Therefore, we fixed this imbalance by merging the current two classes ( 2 and 3 ), naming it newly all class 2 and attributing it a weight of $25 \%$.

We interpolated the Douilly et al. [2013] final velocity model to six layers as an initial model (Figure 3). Owing to the very wide range of station elevations from $534 \mathrm{~m}$ to $-3850 \mathrm{~m}$, we defined the first layer to have a thickness of $5 \mathrm{~km}$ in order to satisfy the VELEST requirement that all stations locate in the first layer [Kissling et al., 1995]. We chose station HCMD as the reference station because of its central location and its high number of recordings, and we performed several inversions where we consider $P$ arrivals only, $S$ arrivals only, and finally $P$ and $S$ arrivals simultaneously. After the third iterations for the $P$-only and the $S$-only inversions, the velocity adjustments are small (in the order of $\sim 0.015 \mathrm{~km} / \mathrm{s}$ ) and the hypocenter adjustments are below observation uncertainty for origin time and within normal noise level for the location. We further removed events that have an azimuthal gap greater than $180^{\circ}$, that have large residuals and that have a root-mean-square (RMS) greater than $0.35 \mathrm{~s}$ for $P$-only inversions and $0.6 \mathrm{~s}$ for $S$-only inversions. We then re-ran the inversion 


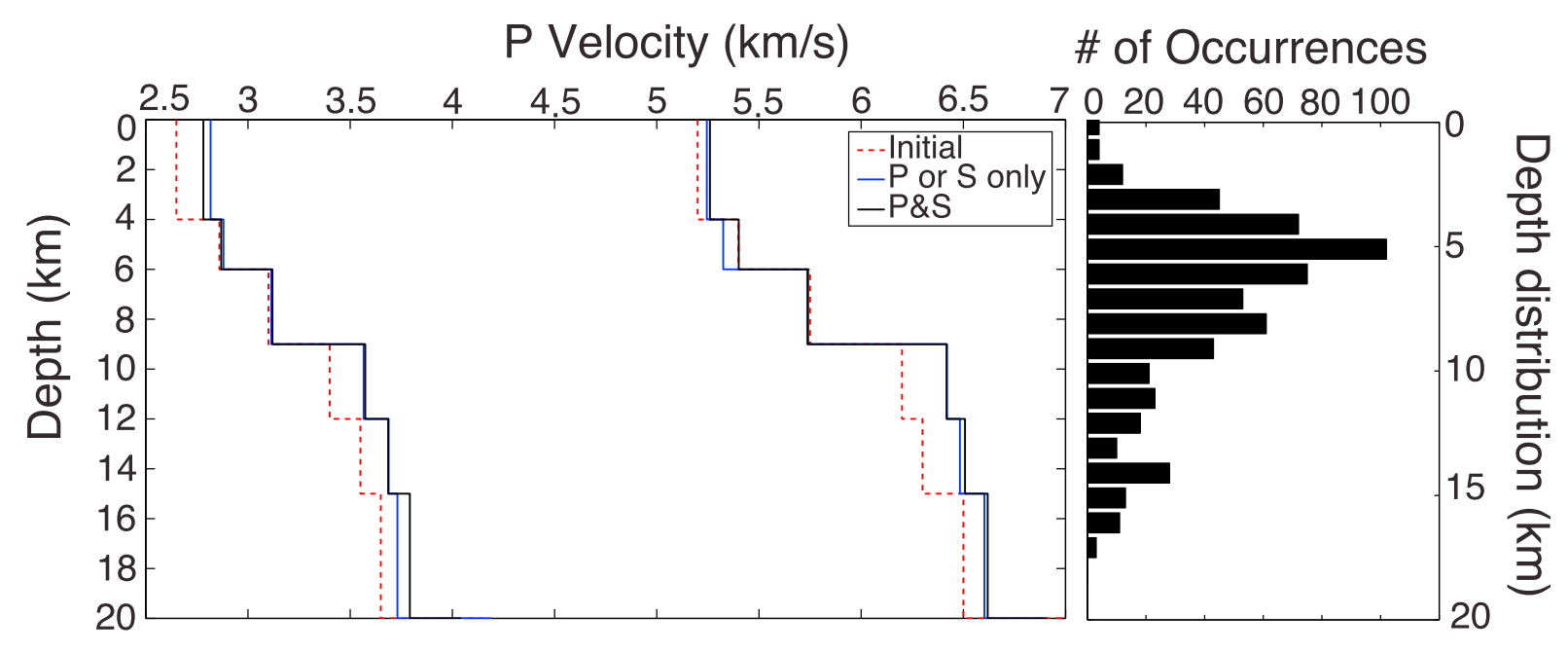

Figure 3. Starting model (red dash line), final velocity model (solid blue line) from the $P$-only (resp. S-only) inversion and final minimum 1-D velocity gradient from the $P$ and $S$ inversion (solid black line). The inset shows a histogram of hypocenter depths from the $P$ and $S$ inversion.
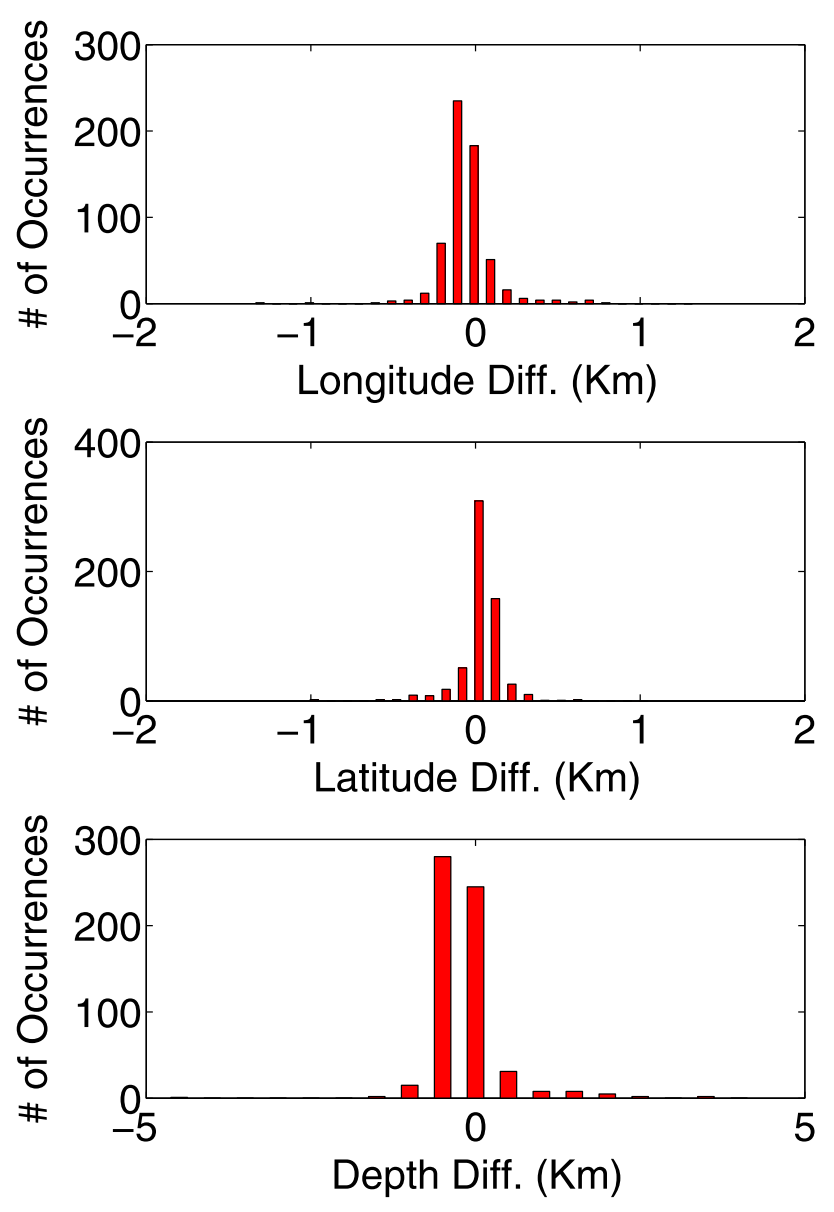

Figure 4. Histograms showing the comparison between the hypocenter locations from the $P$-only inversion and the $P$ and $S$ inversion for the 1-D inversion. with the new subset by using $P, S$, and $P$ and $S$ arrivals, respectively, and compare the final velocity and hypocenter location to ensure the stability of our solutions.

Figure 3 shows the initial $P$ and initial $S$ velocity model (red dashed line), the final $P$-only and final $S$-only inversions (blue line), and the final $P$ and $S$ model from the simultaneous inversion (black line). The $P$-only and $P$ and $S$ (respectively, the $S$-only and $P$ and $S$ ) model converged to the same $V_{p}$ (respectively, $V_{s}$ ) solution. We observed an increase of $0.22 \mathrm{~km} / \mathrm{s}$ at $9 \mathrm{~km}$ depth for $P$ model and $0.17 \mathrm{~km} / \mathrm{s}$ for the $S$ model. At 12 and $15 \mathrm{~km}$ depth we also observed an increase of about $0.11 \mathrm{~km} / \mathrm{s}$ for $P$ velocity and $0.14 \mathrm{~km} / \mathrm{s}$ for $S$ velocity model. There are very few rays that sample the layer below $20 \mathrm{~km}$, and therefore, the initial and final velocities below that depth are unchanged.

We also tested the convergence of the hypocenter for the $P$ inversion only and the $P$ and $S$ simultaneous inversion by tabulating the longitude, latitude, and depth difference (Figure 4). This figure shows that more than 400 events have an epicenter difference of nearly $0.1 \mathrm{~km}$ and the maximum difference in the epicenter is $\sim 1 \mathrm{~km}$ Also, more than 450 

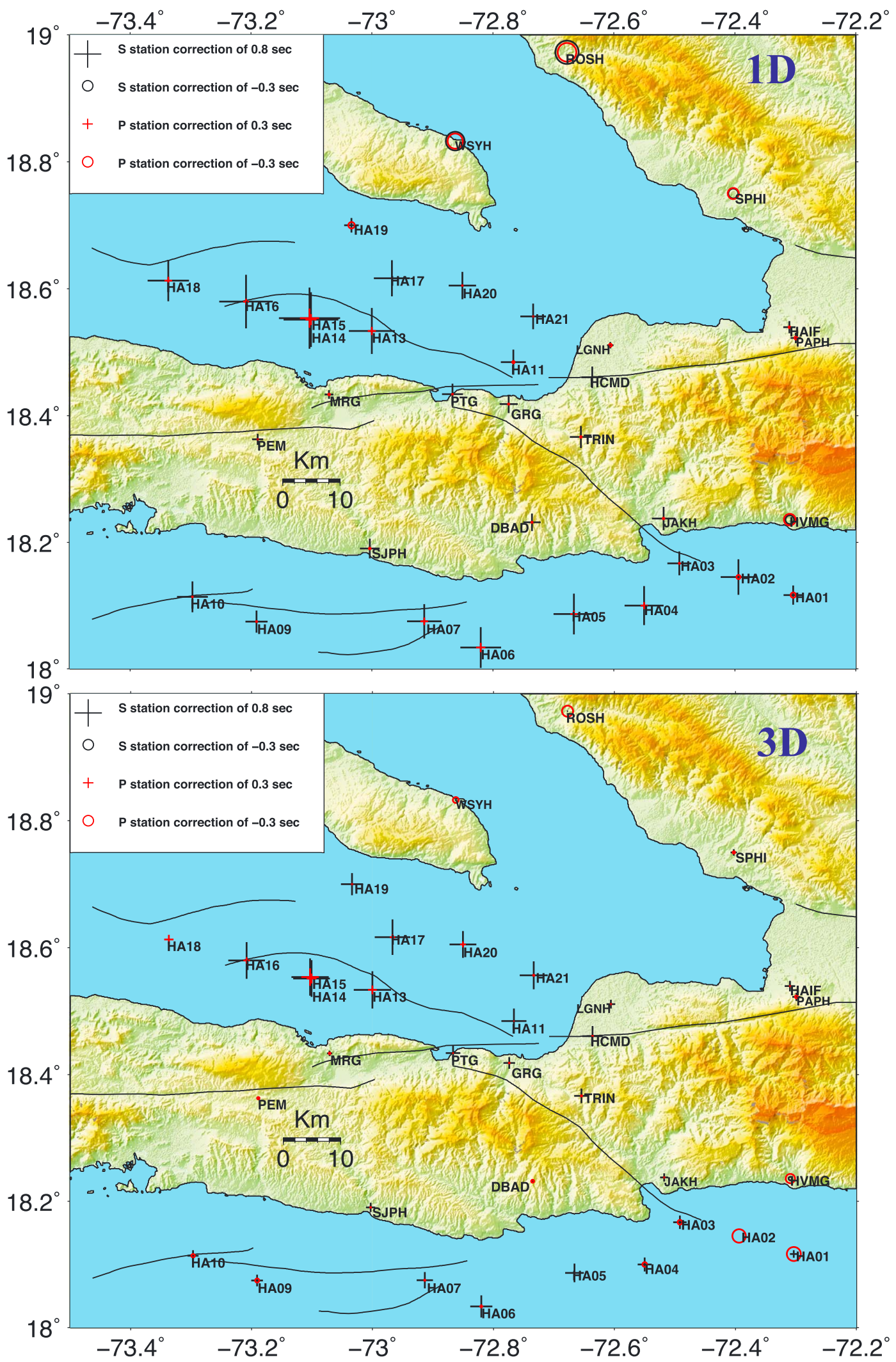

Figure 5. $P$ and $S$ station delays for the (top) 1-D and the (bottom) 3-D joint inversion. Significant positive $S$ station correction is observed for the stations onshore compared to those on land on both models. The 3-D inversion exhibits smaller station correction compared to the 1-D inversion. 

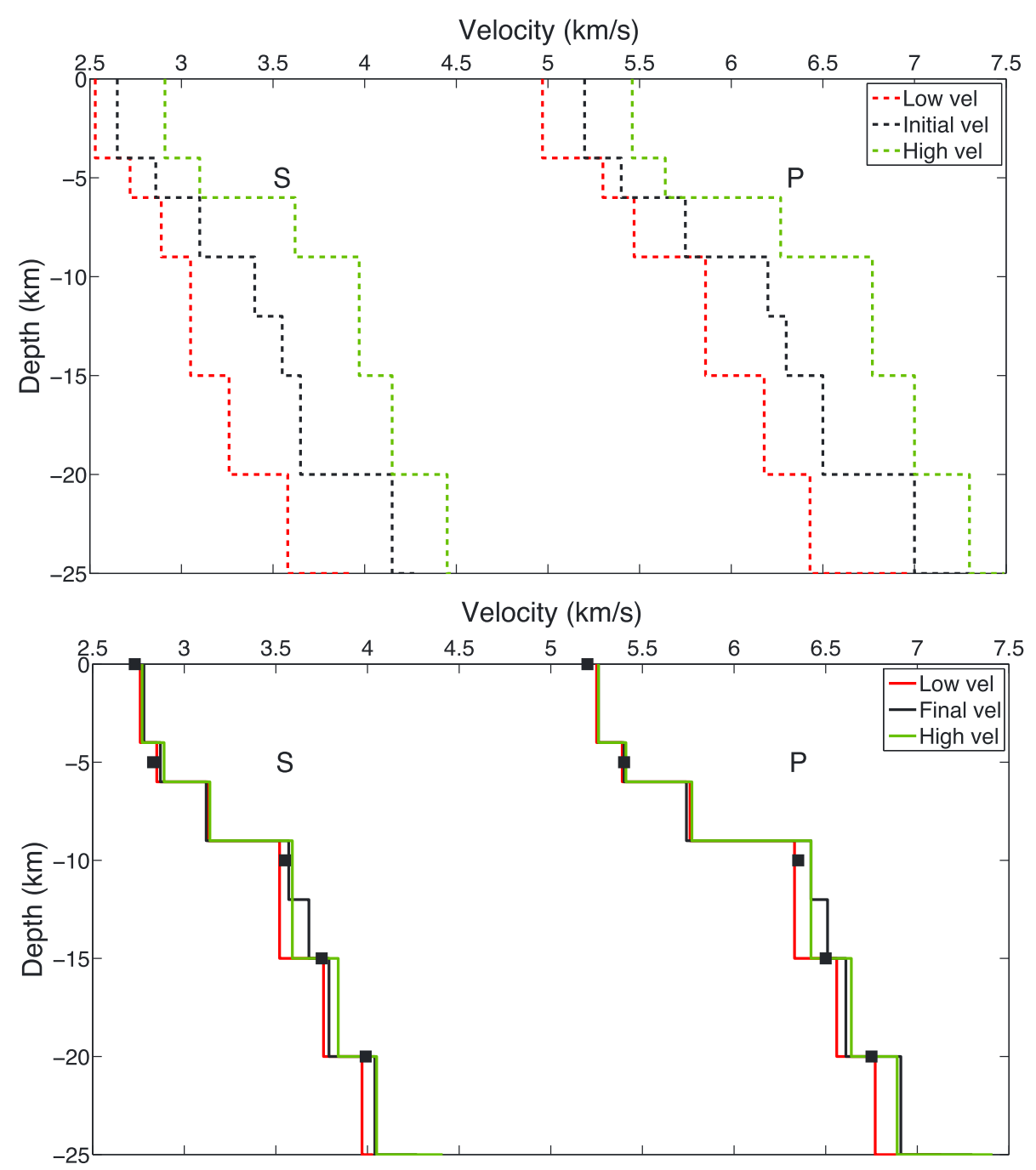

Figure 6. 1-D velocity inversion from three distinct starting models. The red dashed line is a starting low input velocity, the green dashed line is a high input velocity, and the black dashed line is the starting velocity from Figure 3 . The solid lines represent the output velocity from each starting model, respectively. The low (solid red line) and high (solid green line) output velocities converge to the minimum 1-D model (solid black line), which document the stability of the solution. The black squares indicate the vertical grid node distribution for the starting 3-D inversion.

events have their depth difference less than $1 \mathrm{~km}$, and overall, the maximum depth difference is about $3 \mathrm{~km}$, which show the stability of the inversion. The station corrections for this study (Table 1 and Figure 5) are consistent with the result of Douilly et al. [2013], where we find small correction on land and large positive station correction for the lowest offshore stations. This indicates the presence of low-velocity zones and confirms the hypothesis of lateral heterogeneity in the crustal velocity being mostly due to the various basins across the southern peninsula [Momplaisir, 1986; Pubellier et al., 2000].

We also evaluate the RMS with respect to the number of events for all three inversions. The final simultaneous inversion has an average RMS misfit of $0.1 \mathrm{~s}$, which is consistent with the average misfit for the $P$-only inversion. To further investigate the stability of the 1-D velocity model we test different starting models. In addition to the input velocity from the simultaneous inversion of Figure 3, we consider a low (resp. high) $P$ and $S$ starting model as shown in red dashed line (resp. green dashed line) in Figure 6 . The resulting models (solid lines) from low and high input remain very close to the minimum 1-D model (solid black line) which shows great stability of the solution. We also note that within the depth range where we have hypocenters from 0 to $20 \mathrm{~km}$, the layer velocities vary within less than $\pm 0.05 \mathrm{~km} / \mathrm{s}$. 

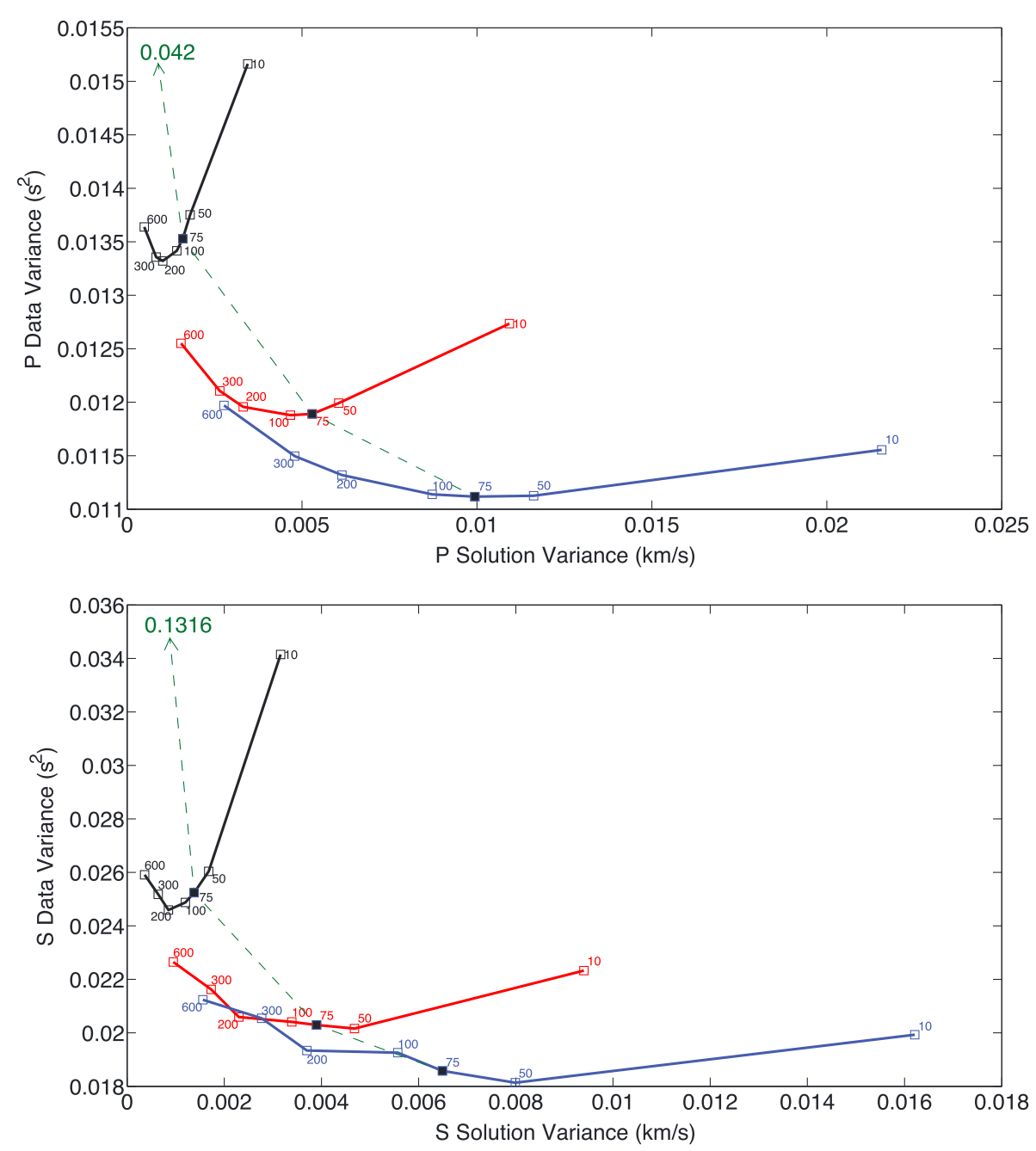

Figure 7. Trade-off curve of solution versus data variance after one (black line), two (red line), and three (blue line) iterations for selecting optimum damping parameter for the $P$ data set and the $S$ data set. The squares marked the chosen damping values tested, and the solid squares indicate the selected value that shows a prominent reduction in the $P$ and $S$ data variance, respectively, without causing a strong increase of the solution variance. The dashed green line links the 75 damping parameter for each iteration and points toward the initial data variance.

The final relocation, using the minimum 1-D $P$ and $S$ model and the data selection requirements described above, yielded a data set of 595 events with $8531 P$ readings and $5923 S$ readings. Those arrivals, including the 1-D velocity model marked as black dot on Figure 6 (which was linearly interpolated at depth between the grid nodes), will be used as a starting point for the 3-D inversion.

\subsection{Local Earthquake Tomography}

Based on the ray coverage for this data set, we consider a $100 \mathrm{~km}$ wide area in the east-west and north-south direction along the southern peninsula of Haiti. This region was gridded with a spacing of $10 \mathrm{~km} \times 10 \mathrm{~km}(11$ nodes $\times 11$ nodes) in the horizontal plane and a spacing of $5 \mathrm{~km}$ in the depth to $20 \mathrm{~km} . P$ arrival times and $S$ minus $P$ times are used with the damped least squares computer algorithm SIMULPS14 [Eberhart-Phillips, 1993; Eberhart-Phillips and Michael, 1998; Evans et al., 1994; Haslinger and Kissling, 2001; Phillips, 1990; Thurber, 1983, 1993] to simultaneously invert for a 3-D $P$ velocity and $V_{p} / V_{s}$ ratio. We set the station corrections to zero upon input to SIMULPS, and we allow the inversion to simultaneously solve for 3-D velocity, hypocenter, and station corrections. The choice of damping for the inversion was determined based on trade-off curves between the data variance and model variance after several iterations [Eberhart-Phillips, 1986]. The trade-off curve was computed based on a wide range of damping values and for one, two, and three iterations, respectively, as shown in Figure 7. The damping values of 100, 75, and 50 showed a 
prominent reduction in the $P$ and $S$ data variance, respectively, with small increase of the model variance mostly for the simulation with three iterations. To narrow the choice of damping, we ran synthetic tests with those three selections and we chose a damping value of 75 for our inversions since it allows better amplitude recovery and less single cell anomalies.

We carried out other quantitative tests to assess the geometrical distribution of rays in our medium and the quality of our data set. SIMULPS implemented the derivative weighted sum (DWS) which measure the relative ray density in the volume by weighting the importance of each ray segment by its distance to the model node [Foulger and Toomey, 1989]. Poorly sampled nodes generated relatively small values for the DWS and well-resolved nodes produced high values. The resolution diagonal element (RDE), also implemented by SIMULPS, measures the dependency of the solution for one model parameter on all the other model parameters. The RDE ranges between 0 to 1 where 0 indicates a poorly to nonresolved region and 1 perfect resolution. The distribution of the RDE values for the 3-D $P$ velocity only and the 3-D $S$ velocity only inversions is superimposed on the synthetic tests shown in Figure 8.

This synthetic test contains elongated anomalies with 5 and $10 \%$ amplitude difference relative to the 1-D velocity. We used this synthetic model to calculate the travel times; we then perturbed the arrival times by incorporating a random Gaussian noise of $\pm 0.04 \mathrm{~s}$ for $P$ (resp. $\pm 0.08 \mathrm{~s}$ for $S$ ) arrivals and invert to recover the anomalies from the synthetic test. The yellow line in this figure marks the region that we consider to be well resolved. We see some vertical leakage between layers 5 and $10 \mathrm{~km}$ in the SW corner. While at $5 \mathrm{~km}$ depth the high-velocity anomaly terminates a bit far north; in the $10 \mathrm{~km}$ layer the low-velocity anomaly is interrupted (refer to mark 1 on Figure 8) due to positive and negative anomalies canceling out which is visible on both $P$ and $S$. In the $10 \mathrm{~km}$ layer, we could not resolve the $W-E$ elongated single-cell wide positive anomaly (mark 2 on Figure 8 ) neither in $P$ nor in $S$, and therefore, we concluded that a single-cell anomaly of $5 \%$ is not resolvable in this specific location. We also note for $P$ velocity that we do well resolve the N-S elongated $10 \%$ high velocity outlined in the $5 \mathrm{~km}$ layer (marked with 3 on Figure 8 ) and with reduced amplitude in layer $15 \mathrm{~km}$ (marked with 4 on Figure 8). For the $S$ velocity, we also see good recovery of anomalies outside the yellow outlined region as marked by 5 on Figure 8 and reduced amplitude recovery at region 6 . We can clearly distinguish the noise-related artifacts (mark by 7) as single-cell anomalies or as features of very low amplitude. We also clearly see the elongated anomalies to be restricted to the fairly well resolved areas.

We also undertook independent synthetic checkerboard test analyses for $V_{p}$ and $V_{s}$ as shown on Figure 9 . We considered the same grid spacing of $10 \times 10 \times 5 \mathrm{~km}$ and calculated the synthetic travel times with alternating input velocities of $\pm 15 \%$ variation compared to the minimum 1-D model. The arrival times were then perturbed with a distributed random noise of $\pm 0.04 \mathrm{~s}$ for $P$ waves and $\pm 0.08 \mathrm{~s}$ for $S$ waves, similar to the synthetic test above, in order to take into account the picking error. To better interpret the checkerboard test, we overlay the RDE isolines (green lines) and the well-resolved region (yellow lines) from Figure 8 . The shallowest part of the model $(0-5 \mathrm{~km})$ have well-resolved regions mostly near the intersection of the Léogâne and Trois Baies faults, which is where the majority of the rays are concentrated (Figure 2). Due to the distribution of hypocenters and stations, we can observe a large well-resolved area at layer $10 \mathrm{~km}$ for both $P$ and $S$. At this depth, the $\mathrm{RDE}=0.4$ for $P$ and $\mathrm{RDE}=0.6$ for $S$ approximately match the outlined well-resolved region marked by the yellow line in Figure 9 . We can also note at 10 and $15 \mathrm{~km}$ depth that some regions outside the outlined area still exhibit some resolution power. Since checkerboard tests mostly reveal the sensitivity rather than the resolution and since the geometry of all anomalies has the same amplitude in just one cell [Haslinger and Kissling, 2001; Spakman et al., 1993], therefore in order to quantitatively address the imaging resolution with respect to our target structure, other characteristic synthetic tests have been performed (Figures S1 and S2 in the supporting information).

Other tests have been explored to check the robustness of the solutions. We have considered a model where we split the entire data set into two groups (subsets 1 and 2) with similar spatial distribution of the hypocenters, invert each group separately, and compare the results to verify if the same structures are present in both data sets. We also test a model where we shift the nodes $45^{\circ}$ to half the distance of two consecutive diagonal nodes. The results from the shifted grid and the splitting data set clearly establish that the overall results are stable. Other resolution strategies, such as finer grid size $(6 \times 6 \times 5 \mathrm{~km})$ and different starting models, have also been conducted to further investigate the quality of our solutions. As an alternative to a homogeneous layered starting model, we consider a model where we average the resolved final velocities output from the 

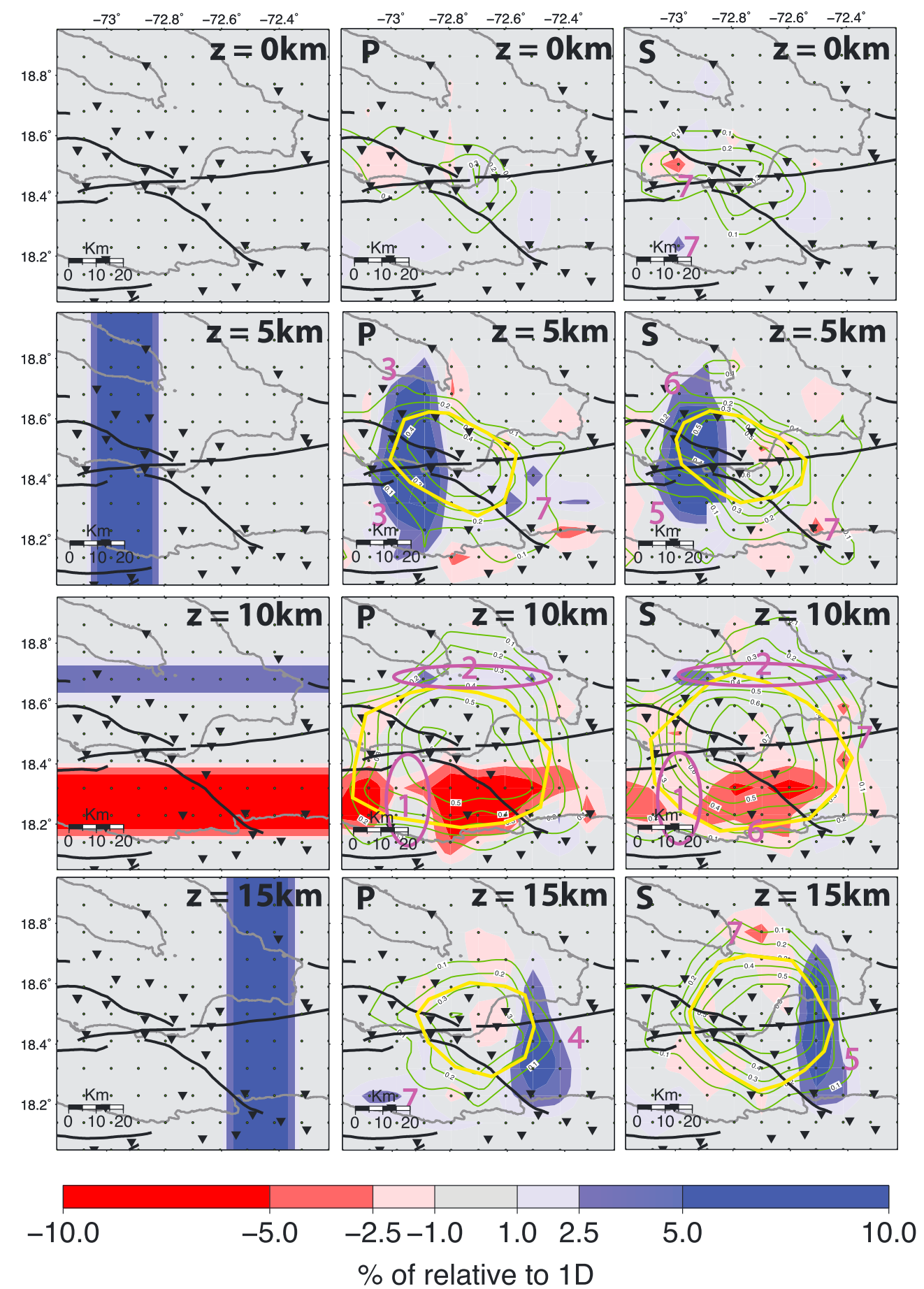

Figure 8. $P$ and $S$ synthetic test with RDE contour lines (green line) resulting from the real data set. The first column shows the synthetic input test, and the second (resp. third) column represents the recovered $P$ (resp. $S$ ) velocity structure. The yellow lines represent the region that we consider to be well resolved. The purple lines and annotations marked specific anomalies that we interpret in the text.

homogeneous case to the north and south of the EPGF. In the well-resolved parts of the model, the EPGF appears to be a boundary mostly at $5 \mathrm{~km}$ where there is a clear change in velocity in the northern part compared to the southern part of the EPGF, as we expect from the morphology of this region. Therefore, if the solution is insensitive to the initial model, it should converge to the same solution where the data require it and perhaps result in a more realistic model in areas where data are few or absent. The output from this 

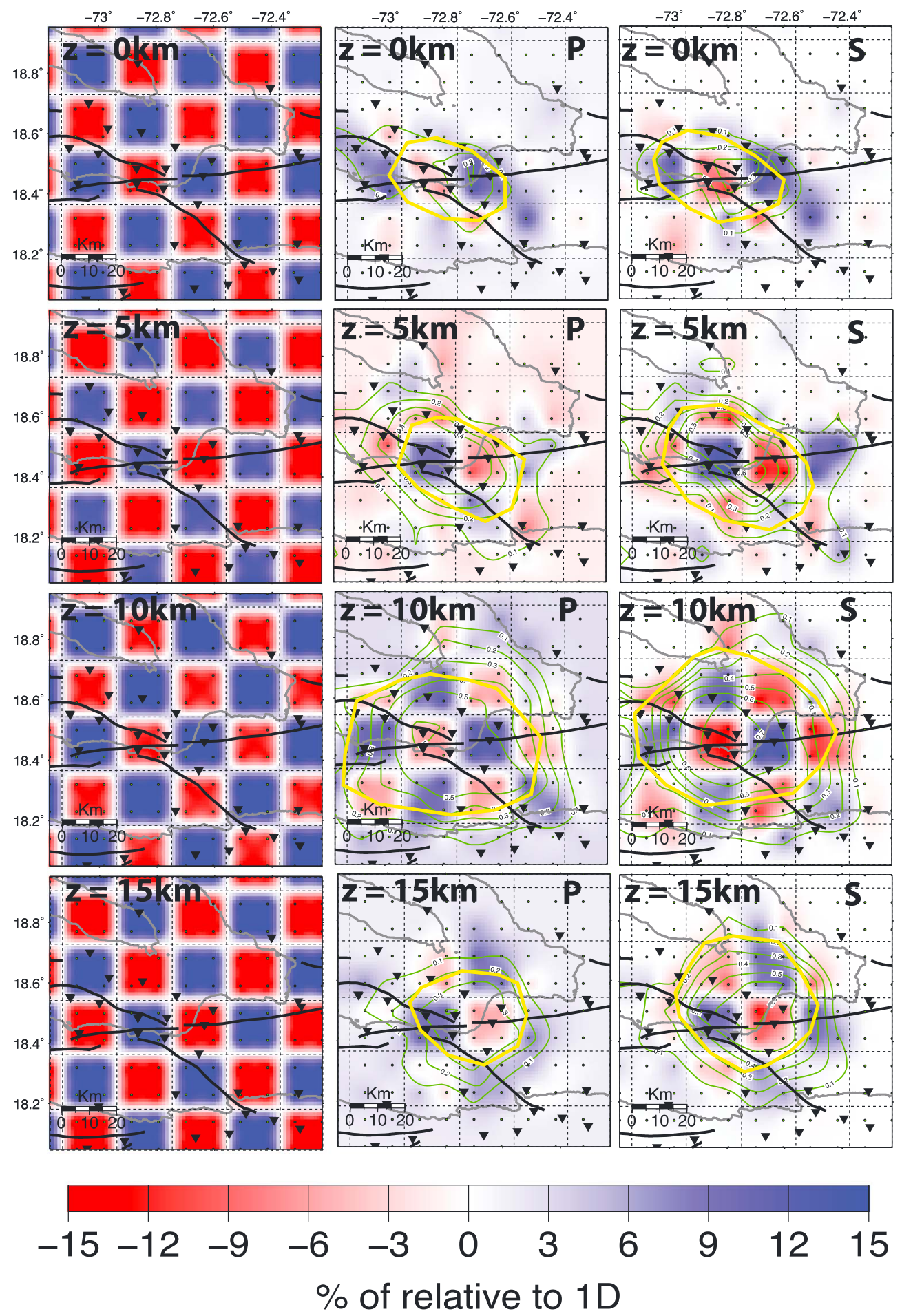

Figure 9. Resolution tests performed for a synthetic checkerboard model. The green lines represent the RDE contour lines, and the yellow lines represent the region that we consider to be well resolved. The first column shows the synthetic input structure, which consists of an alternating positive and negative anomalies of $\pm 15 \%$ variation with respect to the starting $P$ or $S$ velocity model. The second column represents the recovered $P$ velocity structure, and the third column shows the recovered $S$ velocity structure. The bold grey lines represent the coastlines, and the black lines represent the fault traces. See text for more details. 

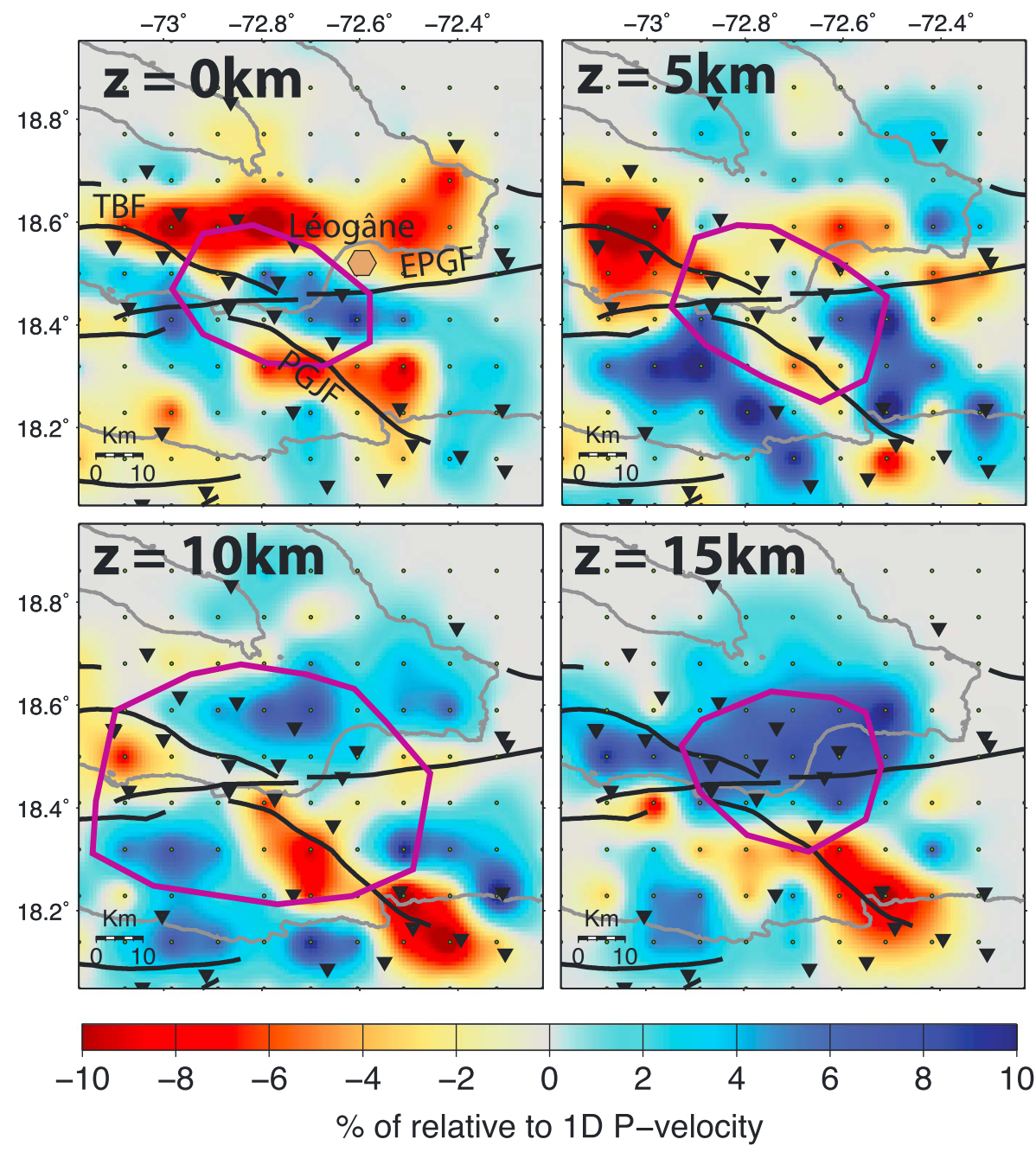

Figure 10. Horizontal slices for the change in $P$ wave velocity structure relative to the stating model at the depths of 0,5 , 10 , and $15 \mathrm{~km}$. The bold grey lines represent the coastlines, and the black lines represent the fault traces. The green dots indicate the inversion nodes. The inverted triangles represent the seismic stations. The pentagon symbol indicates the location of the city of Léogâne. The purple contour lines denote regions where we considered to be well resolved as denoted by the yellow lines in Figures 8 and 9.

alternate input velocity is consistent with the results of the homogeneous starting model where the same distinctive features can be observed on both models. Those resolution tests have shown that clear features can be recovered from this data set at a depth up to $15 \mathrm{~km}$ in the southern peninsula, both onshore and offshore.

\section{Tomography Results}

The final $P$ wave and $S$ wave velocities (Table $S 1$ in the supporting information) are presented in several horizontal depth slices shown in Figures 10 and 11. As explained above, we consider a $10 \mathrm{~km}$ horizontal grid spacing and we jointly invert the travel times for the hypocenter, the 3-D crustal velocity, and the station corrections. The station delays from the 3-D inversion are smaller than the station delays from the 1-D inversion but consistent (Figure 5). We only show results from 0 to $15 \mathrm{~km}$ depth, where resolution tests indicate sufficient ray coverage, and we only draw conclusions in the well-resolved regions illustrated in Figures 8 and 9. The tomography model shows distinct lateral variation in seismic velocities at several depth ranges.

Near the surface, distinct zones of increase and decrease in velocity can be observed. Offshore near the Trois Baies fault, we observed a decrease of about $6 \%$ in $V_{p}$ in the northern part of the fault and an increase of about $5 \%$ in the southern region. This fast-velocity zone seems to continue further south in the region of high 

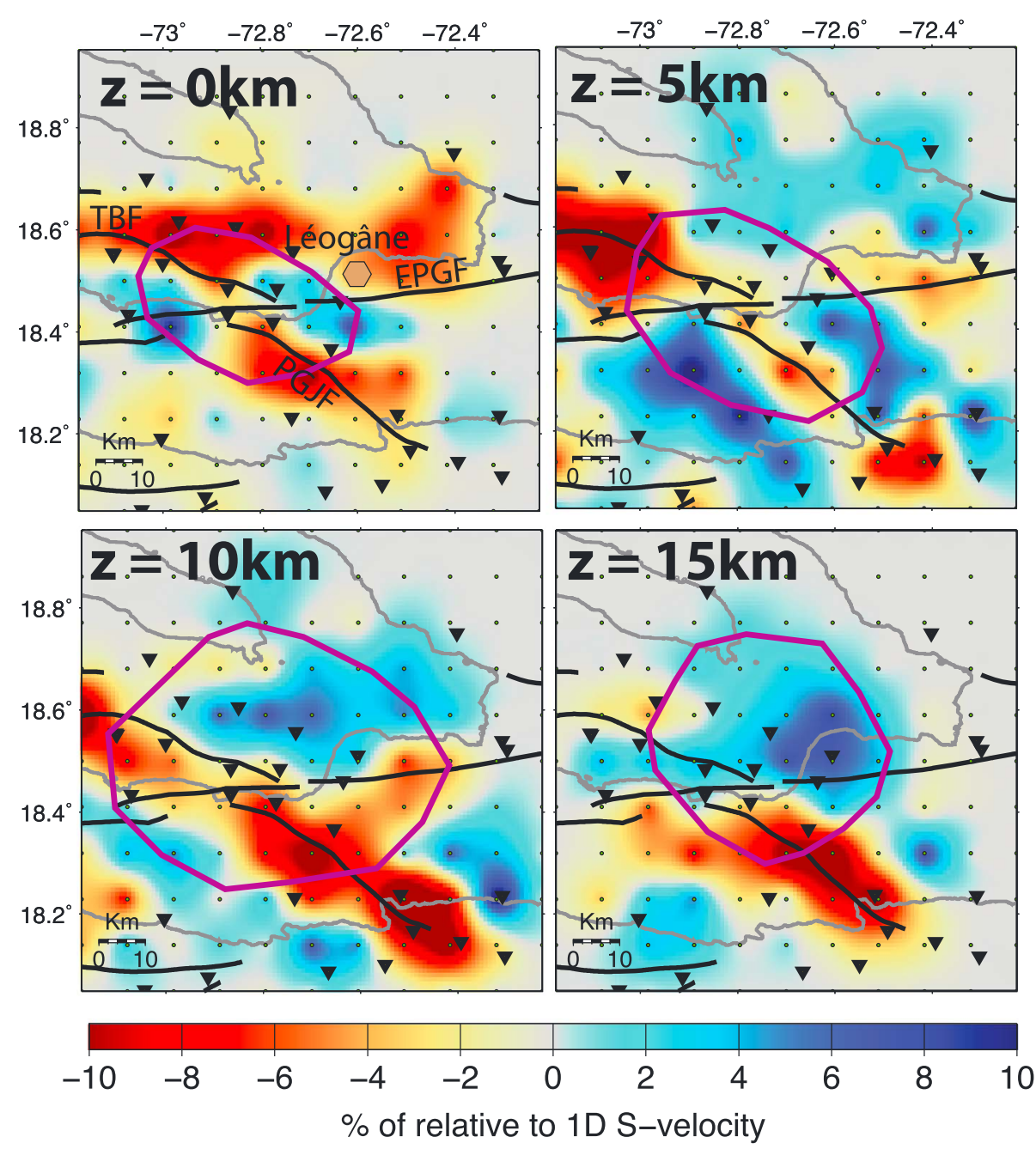

Figure 11. Horizontal slices for the change in $S$ wave velocity structure relative to the stating model at the depths of 0,5 , 10 , and $15 \mathrm{~km}$. The bold grey lines represent the coastlines, and the black lines represent the fault traces. The green dots indicate the inversion nodes. The inverted triangles represent the seismic stations. The pentagon symbol indicates the location of the city of Léogâne. The purple contour lines denote regions where we considered to be well resolved as denoted by the yellow lines in Figures 8 and 9 .

topography around latitude 18.3 and longitude -72.9 . We also observed patches of decrease in velocity near the $\mathrm{N} 125^{\circ}$ fault mapped by Mercier de Lépinay et al. [2011], which we refer to in the figures as the Petit-Goâve-Jacmel fault (PGJF). Similar structures are detected in the $S$ wave velocity model. We observed a prominent low-velocity zone (LVZ), about a 9\% decrease from the initial $S$ velocity model, above the Trois Baies fault. These features are also noticeable at greater depths. At $5 \mathrm{~km}$ depth we can distinguish a broad LVZ offshore near Gonave island of about $6 \%$ decrease in the $V_{p}$ and $10 \%$ in the $V_{s}$ models. This LVZ seems to correlate with a region of thick submarine sediments in the Canal-du-Sud basin [McHugh et al., 2011; Momplaisir, 1986]. We also observe a low-velocity zone in the northern part of the Léogâne fault and on the Petit-Goâve-Jacmel fault. The $V_{p}$ and $V_{s}$ models also reveal fast-velocity zones on opposite sides of the PGJF, in regions of high topography (latitude 18.3, longitude -72.9 and latitude 18.35 , longitude -72.5 on Figure 10). On the eastern part of the southern peninsula, the EPGF delineates a clear boundary between regions of decreased (near Léogâne) and increased velocity structure.

The $10 \mathrm{~km}$ horizontal depth slice is mostly marked by clear broad low-velocity zones mostly in the $S$ velocity and some high-velocity zones in the $P$ velocity. Near the PGJF, we can distinguish a continuous NW-SE oblique decrease of $\sim 6 \%$ drop in the $V_{p}$ and $\sim 10 \%$ in $V_{s}$ model. We also observed a W-E trending high-velocity anomaly along the northern side of the fault in the $V_{p}$ and $V_{s}$ models, very similar to what we see in layer 
$15 \mathrm{~km}$. The $15 \mathrm{~km}$ depth layer is less well resolved compared to the shallower layers. Nevertheless, we can still observe a LVZ near PGJF on both $P$ and $S$ wave velocity and a pronounce high-velocity increase mostly in the $V_{p}$ model near the city of Léogâne and offshore near the canal-du-Sud. Overall, we observed that highvelocity amplitudes generally to be stronger in $P$ velocity and the low-velocity amplitudes to be stronger in $S$ velocity.

Our results show a pronounced narrow low-velocity zone from $5 \mathrm{~km}$ to $15 \mathrm{~km}$ depth to follow the oblique fault from $18.1 \mathrm{~N} / 72.5 \mathrm{~W}$ to $18.4 \mathrm{~N} / 72.9 \mathrm{~W}$ and possibly continuing across the $\mathrm{W}-\mathrm{E}$ main fault along the oblique fault toward NW. As noted before, this low-velocity anomaly is visible with stronger negative anomalies in $S$ than in $P$. The second large-scale structure reliably imaged and clearly visible both in $P$ and in $S$ is the pronounced velocity contrast (higher velocity to the north) across the main W-E trending fault from $7 \mathrm{~km}$ depth to below $15 \mathrm{~km}$ depth. The SE-NW trending low-velocity band could be a gouge zone along the fault, while the high-velocity anomaly corresponds with two specifically different crustal blocks north and south to now be juxtaposed along the main W-E trending fault. The low-velocity anomalies at shallow depths north of the main fault could be related to the thickened sediments in this basin.

Our model could not resolve the Moho discontinuity since according to previous studies from regional seismic data and receiver functions analysis [McNamara et al., 2012], this region has a crustal thickness of $\sim 20 \mathrm{~km}$ and our model has low resolution at these depths. In our 3-D analysis, we also invert for the hypocenter location of each aftershock. We compared the hypocenter location and the RMS values from the 1-D inversion to the 3-D. We found that the average epicentral variation among the two is very small $(\sim 1.1 \mathrm{~km})$ but despite the average $\sim 1.5 \mathrm{~km}$ change in the hypocentral depth and the $32 \%$ reduction of the average RMS in the 3-D relocations compared to the 1-D, the 3-D velocity model did not alter the sharp fault geometry delineated by the aftershocks as concluded by Douilly et al. [2013].

\section{Discussion}

This study presents the first three-dimensional $P$ and $S$ velocity structures for the southern peninsula of Haiti from aftershock travel time arrivals following the 2010 Haiti earthquake. Our study region surrounding the 2010 earthquake uncovered high-velocity regions mostly in the $P$ velocity, but the $S$ velocity is mostly governed by fault-related low-velocity zones. In studies of the 1966 Parkfield, 1995 Northridge, and 1989 Loma Prieta earthquakes, tomography results showed a correlation between aftershock activity and these faster velocity crustal features [Lees and Malin, 1990; Thurber et al., 1995; Zhao and Kanamori, 1995]. Similar correlation was also observed along other segments of the San Andreas Fault [Michael and Eberhart-Phillips, 1991; Nicholson and Lees, 1992]. But recent tomography studies in California have found aftershocks on both fast- and slow-velocity anomalies [Allam and Ben-Zion, 2012; Hauksson, 2000; Lin et al., 2007, 2010]. Lin et al. [2007] have found that aftershocks below $5 \mathrm{~km}$ depth tend to occur in region of fast $P$ velocity anomaly, whereas aftershocks near the $15 \mathrm{~km}$ depth tend to lie in slow $P$ velocity anomaly. Furthermore, Allam and BenZion [2012] stated that off-fault regions with lack of seismicity seem to correlate with high seismic velocity but areas of focus seismicity seem to occur in region of reduced seismic velocity. In our study, we were not able to differentiate those characteristics at this scale. The seismicity pattern following the 2010 Haiti earthquake occurred in both regions of fast and slow velocities (Figures S3 and S4). However, at shallower depth $(<10 \mathrm{~km})$, we observe that more aftershocks are located in regions of low velocity, while the seismicity at greater depth $(>10 \mathrm{~km})$ is mostly located in regions of fast-velocity material. This might constitute a direct effect of the limited seismic record for this region or an effect of the grid spacing of our tomography study compared to the greater resolution of the California studies in which it was possible to detect small and localized anomalies. Nevertheless, we can distinguish clear horizontal polarity velocity contrasts across TBF, PGJF, and EPGF segments (Figures 11 and 12), which could be associated with bimaterial fault interfaces, similar to several faults in Southern California [Allam and Ben-Zion, 2012; Allam et al., 2014]. Several studies have shown the influence of bimaterial fault interfaces on rupture directivity [Ben-Zion and Shi, 2005; Shi and Ben-Zion, 2006]. Shi and Ben-Zion [2006] have found that bimaterial interfaces, with a certain degrees of contrast, generate dynamic dilatation at one rupture tip and dynamic compression at the other. This implies that the rupture is likely to die quicker in the direction of compression, while it continues to grow in the opposite direction. Thus, we could infer a preferred rupture direction during a large earthquake across each of our fault structures due to the influence of the velocity contrast. At the upper layers, all three faults (PGJF, TBF, and 


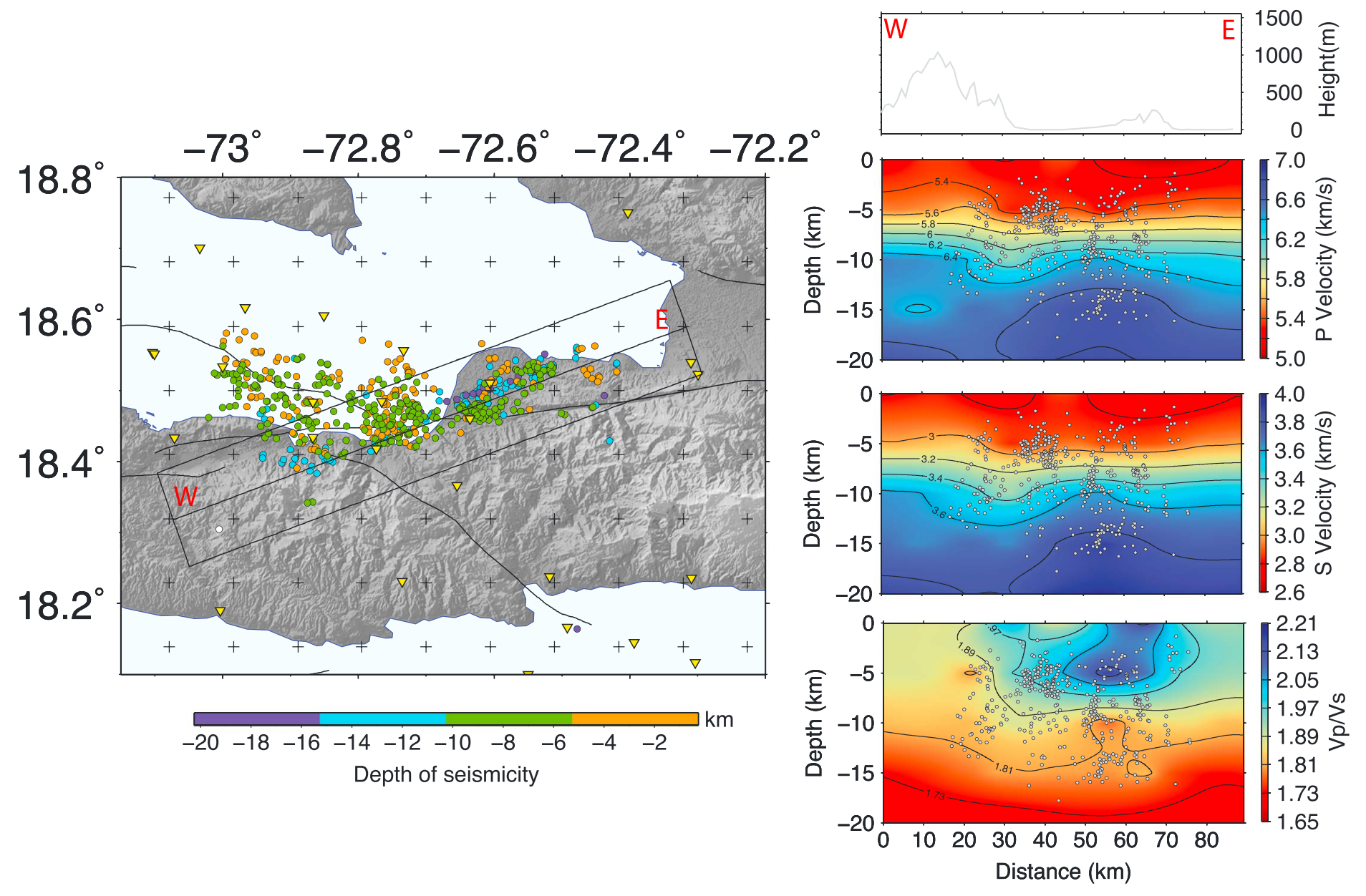

Figure 12. Aftershock distribution from the tomographic inversion and cross sections of $V_{p}, V_{s}$, and $V_{p} / V_{s}$ ratio along the W-E directions, parallel to the main fault trace delineated by the aftershocks, as indicated in the map view. The hypocenters in the map view are coded by hypocenter depth. Hypocenters within the rectangular box are included in each cross section. The box with the grey lines indicates the topographic elevation along the cross sections. The black lines in the $V_{p}$ $V_{s}$ and $V_{p} / V_{s}$ ratio cross sections, respectively, represent contour lines of the absolute $V_{p}, V_{s}$ and $V_{p} / V_{s}$ ratio values, respectively, with depth.

EPGF) are delimited by low-velocity structure in the northern side and faster-velocity anomaly in the southern one. This suggest that the preferred rupture direction, along those faults, is west to east due to the dynamic dilatation generated at the eastern side compared to the western one. However, this was not the case during the 2010 Haiti event. Rupture on the Léogâne fault had unclamped the Trois Baies fault (TBF) located west of the rupture [Symithe et al., 2013]. A possible explanation for the east-west rupture direction during this event is the reverse polarity observed near Léogâne at greater depth (Figure 10) and also the fact that the rupture did not reach the surface. At this depth, the fast-velocity anomaly is located north of the EPGF compared to south at shallower depth, which is consitent to a east-west preferred rupture direction.

Bimaterial fault interfaces also influence ground motion during an earthquake [Ben-Zion, 2001]. Therefore, this result is vital to assess ground motion level from potential earthquake scenarios mainly on the EPGF not only because this fault still remains a major seismic threat for the nearby cities in southern Haiti [Calais et al., 2010; Douilly et al., 2015; Prentice et al., 2010; Symithe et al., 2013] but also because sedimentary basin could trap the energy and significantly amplify the ground shaking [Day et al., 2006; Olsen, 2000; Wald and Graves, 1998]. As an example, Komatitsch et al. [2004] used a spectral element method to simulate ground motion in the Los Angeles basin and their results uncover large amplification within the basin for their 3-D simulation with respect to their 1-D case. In our study region, the low-velocity zone underneath Léogâne could cause similar effects by enhancing the ground motion during large earthquakes and endanger the infrastructure that sits atop them. 


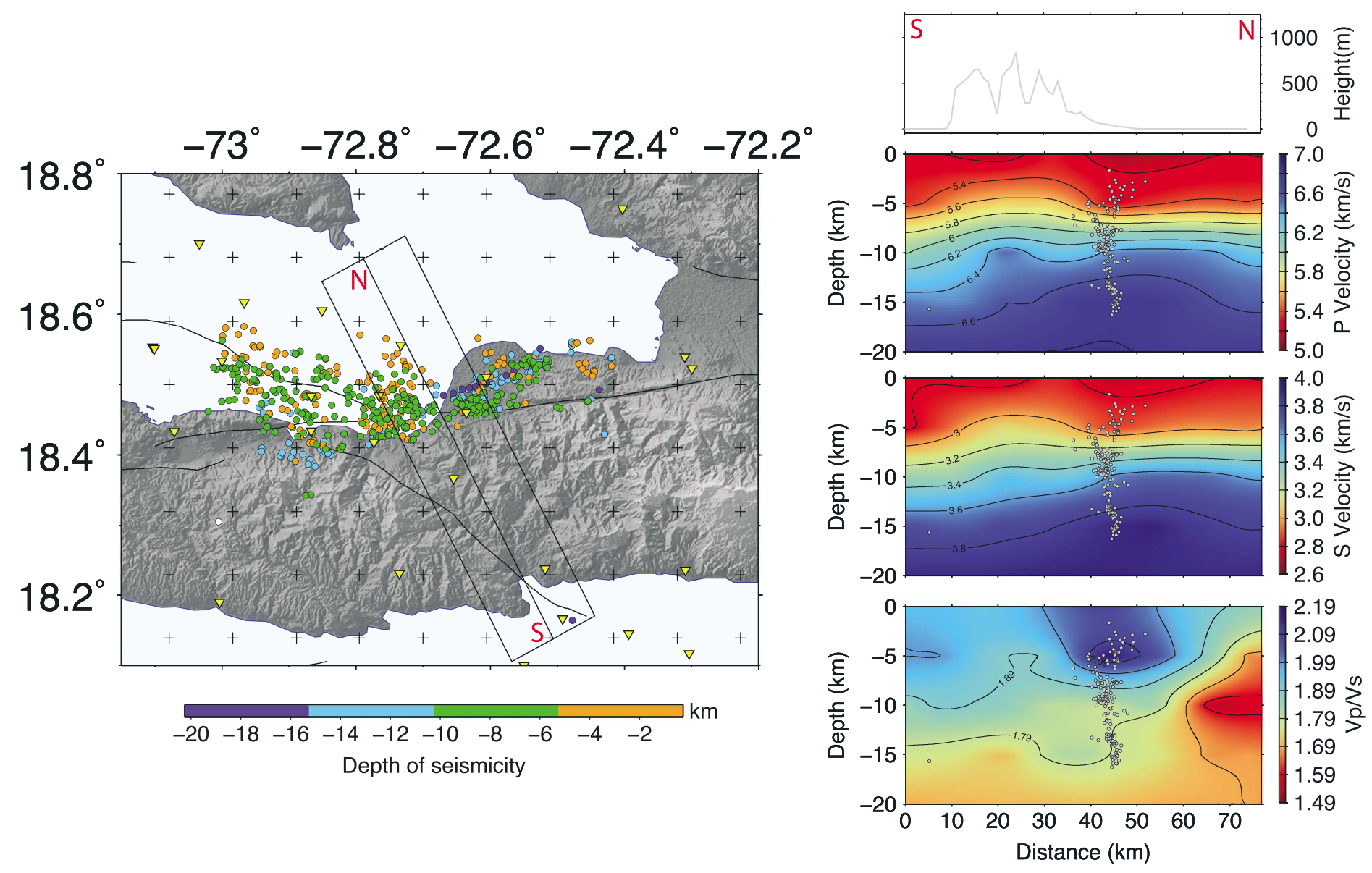

Figure 13. Aftershock distribution from the tomographic inversion and cross sections of $V_{p}, V_{s}$, and $V_{p} / V_{s}$ ratio along the N-S directions, perpendicular to the main fault trace delineated by the aftershocks, as indicated in the map view. The hypocenters in the map view are coded by hypocenter depth. Hypocenters within the rectangular box are included in each cross section. The box with the grey lines indicates the topographic elevation along the cross sections. The black lines in the $V_{p}, V_{s}$ and $V_{p} / V_{s}$ ratio cross sections, respectively, represent contour lines of the absolute $V_{p}, V_{s}$, and $V_{p} / V_{s}$ ratio values, respectively, with depth.

Figures 12 and 13 show cross sections parallel and perpendicular, respectively, to the 2010 earthquake rupture. Under the city of Léogâne and at shallow depth (upper $5 \mathrm{~km}$ ), a clearly distinguished low-velocity anomaly is present, which has a $P$ wave velocity in the range of $5.0-5.3 \mathrm{~km} / \mathrm{s}$. We associate this low-velocity zone to the quaternary sedimentary basin as mentioned by Pubellier et al. [2000]. Similar low-velocity contrast in shallow layers is observed in California along the San Andreas Fault, the Los Angeles basin, the Salton Trough, and the San Jacinto fault zone from tomographic inversion [Allam and Ben-Zion, 2012; Chen et al., 2007; Hauksson and Haase, 1997; Lees, 1990; Lewis et al., 2005; Magistrale et al., 1996; Shapiro et al., 2005; Tape et al., 2009; Yang et al., 2014]. In our study we also observed a correlation between the low-velocity structure and upper depth limit of seismic activity. Aftershocks occurred below the LVZ, ceasing at the zone's lower boundary (Figures 12 and 13). We hypothesized that this low-velocity anomaly could act as a barrier to aftershocks reaching the surface, but we do not dismiss the possibility that the EPGF itself could act as a barrier to the aftershocks since there are very few aftershocks south of that fault or that this correlation could be an artifact of the coarse vertical layering of the model. Future studies such as controlled source experiments [Hardebeck, 2010], ambient noise tomography [Shapiro and Campillo, 2004; Shapiro et al., 2005], or teleseismic tomography [Bezada et al., 2013] with a higher resolution would be able to clarify this assertion.

The low-velocity feature near the city of Léogâne has $V_{p} / V_{s}$ ratio in the range of 2.00-2.19 (Figure 12), which corresponds to a rise of 10 to $20 \%$ compared to the $V_{p} / V_{s}$ ratio at the same depth outside this region and the $V_{p} / V_{s}$ ratio along the depth distribution. High $V_{p} / V_{s}$ ratio is also observed in Parkfield region around the San Andreas Fault from double difference tomography [Zhang et al., 2009]. Similar to our findings, the shallow high- $V_{p} / V_{s}$ zone from Zhang et al. [2009] correlates with region of low- $V_{p}$ 
and low- $V_{s}$ structures. Thurber et al. [1995] also observed a rapid increase of $V_{p} / V_{s}$ with depth for the Loma Prieta rupture, which they hypothesized being due to a change in elastic properties. They also infer that a change in elastic properties with depth could explain the upward termination of the Loma Prieta earthquake. The 2010 Haiti earthquake and the 1989 Loma Prieta earthquake share several similarities in tectonics and earthquake rupture processes [Douilly et al., 2013, 2015; Symithe et al., 2013]. They both involved rupture initiation on smaller blind thrust fault adjacent to major strike-slip fault without transferring to the main fault. They both also involved patches of slip that did not reach the surface. We could therefore infer that the significant decrease in shear modulus as the surface is approached, as proposed by Thurber et al. [1995], might explain the termination of the upper limit of the rupture and the reason why there was no surface rupture [Prentice et al., 2010].

Another possible explanation for why the Léogâne rupture failed to reach the surface is that the Léogâne Fault terminates at the EPGF where they meet in the subsurface. The termination of the 1994 Northridge rupture at the depth where it propagated into the San Fernando fault is a similar case [Mori et al., 1995; Wald et al., 1996]. For this event, Zhao and Kanamori [1995] inferred that an abrupt change in velocity and the strength of the crust when the San Fernando fault was encountered might also explain the arrest of Northridge aftershocks.

The 3-D $P$ and $S$ velocity results show a broad low-velocity zone along the Petit-Goâve-Jacmel fault, most prominently around $10 \mathrm{~km}$ depth (Figures 10 and 11). Low-velocity anomalies are sometimes associated with broad zones of deformation or fault zones [Eberhart-Phillips and Bannister, 2002]. Previous studies have found low velocities on segments of the San Andreas Fault and along the New Madrid fault zone [Mooney and Ginzburg, 1986; Thurber et al., 1997]. However, low-velocity zones can also represent compositional variations, high fluid pressure, or high pore pressure [Eberhart-Phillips and Bannister, 2002; Zhao and Kanamori, 1995] [Lin et al., 2010; Ryberg and Fuis, 1998]. Either hypothesis provides a possible explanation as to why we observed a midcrustal velocity reduction along the PGJF. Some studies mentioned that low-velocity anomaly sometimes occurred on active fault systems [Eberhart-Phillips and Bannister, 2002; Eberhart-Phillips and Reyners, 1997], but in our case study, despite the fact that Aiken et al. [2016] have found light correlation between tremor sources and the low-velocity anomalies along the PGJF, we do not have enough information to confirm if the PGJF is active or not. Nevertheless, at $10 \mathrm{~km}$ depth, this anomaly seems to extend further offshore to the south and to the north. Offshore to the north, the LVZ is aligned with the thrust south dipping Trois Baies fault where triggered aftershocks were observed during this event [Symithe et al., 2013].

\section{Conclusions}

We performed a joint inversion for a 3-D $P$ and $S$ velocity structure and hypocenter location by using arrival times from 595 aftershocks following the 2010 Haiti earthquake. We considered a $10 \times 10 \mathrm{~km}$ grid spacing and used the damped least squares computer algorithm SIMULPS14 to simultaneously invert for 3-D $P$ velocity, $V_{p} / V_{s}$ ratio, and hypocenter location. Other inversion techniques, such as double difference tomography (TomoDD) [Zhang and Thurber, 2003], ambient noise tomography [Shapiro et al., 2005], full waveform inversion [Tape et al., 2009], surface wave inversion [Fang et al., 2015], and joint body wave and Rayleigh wave inversion [Fang et al., 2016], may be applied to improve the 3-D velocity model of the southern peninsula when respective data become available. Since our station network consisted primarily of short period stations (refer to Douilly et al. [2013] for more details), at present only TomoDD could potentially be applied to locally improve resolution of the velocity structure within the cloud of hypocenters. Nevertheless, it will not change the main findings from this regional study. More data such as active sources are required in addition to this data set to obtain higher resolution of finer-scale structure in this region.

We performed several tests in order to check the robustness of the solutions and establish that the regions anomaly can be resolved by the model. The three upper layers $(0,5$, and $10 \mathrm{~km})$ are sufficiently well resolved that features can be well recovered at those depths. Resolution is poor at $15 \mathrm{~km}$ except near Léogâne where most rays are concentrated, and we have no resolution at $20 \mathrm{~km}$ depth. The model contains strong lateral variation onshore and offshore of the peninsula near the Trois Baies fault. The offshore low-velocity anomaly resides primarily at $5 \mathrm{~km}$ depth and correlates with the location of thick sediments in the submarine basin. At $10 \mathrm{~km}$ depth, we found a sharp $\mathrm{N} 125^{\circ}$ low-velocity zone running along the Petit-Goâve-Jacmel fault (PGJF) that extends offshore to the Trois Baies fault. The Petit-Goâve-Jacmel fault, which was a suspected fault 
based on geological observations [Mercier de Lépinay et al., 2011], seem to be a major fault according to the tomography result. However, we cannot say based on the tomography alone whether it is active or not. This midcrustal anomaly along the PGJF and Trois Baies faults may indicate a broad zone of deformation or the presence of fluid in the upper crust, or it could correspond to internal features of the Oceanic Plateau. Zhao and Kanamori [1995] stated that fast-velocity anomalies are sometimes associated with more brittle and competent rock in the crust, and therefore, we believed that those low-velocity zones could suggest that the fault zones in the southern peninsula are not intact but in fact consist of high degree of fracture zones.

A fast-velocity anomaly is detected in region of high topography on both side of the PGJF and in the deeper layer ( $15 \mathrm{~km}$ depth) mostly onshore under the city of Léogâne and offshore in the Canal-du-Sud. Fast-velocity zones are generally associated with more brittle and competent rock, and in contrast, low-velocity zones indicate more fractured region [Lees and Nicholson, 1993; Scott et al., 1994; Zhao and Kanamori, 1995]. We also observed a decrease in velocity in the upper layers near Léogâne, and the $V_{p} / V_{s}$ ratio revealed a drastic increase consistent with a change in material property associated with the sedimentary basin that underlie the city of Léogâne. Since Port-au-Prince is underlain by a similar basin [Pubellier et al., 2000] and although our model did not extend to Port-au-Prince, we hypothesize that crustal velocities similar to those underlying Léogâne are present there. A detailed investigation of crustal structure is necessary in order to confirm this assertion.

\section{Acknowledgments}

This research is supported by a COCONet Graduate Fellowship from UNAVCO to R.D. We acknowledge the support of INSU/CNRS, IRD, and IFREMER which allowed the Haiti OBS mission. We are grateful to Marie-Paule Bouin, John G. Armbruser, and Susan S. Hough, who participated either in the station deployment or the picking of the arrivals. The USGS and NRCAN seismic data can be downloaded from IRIS (http://www.iris.edu/SeismiQuery/ breq_fast.htm), and the IPGP and OBS data are available on RESIF Seismic Data Portal (http://seismology.resif.fr). We thank the Bureau of Mines and Energy and the Faculty of Science of the State University of Haiti for their support throughout this project. We appreciated helpful comments from the associate editor, Amir Allam, and an anonymous reviewer that led to the improvements of this manuscript. The figures were generated by using GMT [Wessel and Smith, 1998].

\section{References}

Aiken, C., K. Chao, H. Gonzalez-Huizar, R. Douilly, Z. Peng, A. Deschamps, E. Calais, and J. S. Haase (2016), Exploration of remote triggering: A survey of multiple fault structures in Haiti, Earth Planet. Sci. Lett., 455, 14-24, doi:10.1016/j.epsl.2016.09.23.

Allam, A., and Y. Ben-Zion (2012), Seismic velocity structures in the Southern California plate-boundary environment from double-difference tomography, Geophys. J. Int., 190, 1181-1196.

Allam, A., Y. Ben-Zion, I. Kurzon, and F. Vernon (2014), Seismic velocity structure in the hot springs and trifurcation areas of the San Jacinto fault zone, California, from double-difference tomography, Geophys. J. Int., 198, 978-999.

Baher, S. A., and Davis, P. M. (2003), An application of seismic tomography to basin focusing of seismic waves and Northridge earthquake damage, J. Geophys. Res., 108(B2), 2122, doi:10.1029/2001JB001610.

Bellerive, J. M. (2010), Haiti Earthquake PDNA: Assessment of Damage, Losses, General and Sectorial Needs, Port Au Prince Haiti. [Available at https://www.gfdrr.org/sites/gfdrr/files/GFDRR_Haiti_PDNA_2010_EN.pdf, last accessed September 2016.]

Ben-Zion, Y. (2001), Dynamic ruptures in recent models of earthquake faults, J. Mech. Phys. Solids, 49, 2209-2244.

Ben-Zion, Y., and Z. Shi (2005), Dynamic rupture on a material interface with spontaneous generation of plastic strain in the bulk, Earth Planet. Sci. Lett., 236, 486-496.

Bezada, M., E. Humphreys, D. Toomey, M. Harnafi, J. Dávila, and J. Gallart (2013), Evidence for slab rollback in westernmost Mediterranean from improved upper mantle imaging, Earth Planet. Sci. Lett., 368, 51-60.

Calais, E., A. Freed, G. Mattioli, F. Amelung, S. Jónsson, P. Jansma, S.-H. Hong, T. Dixon, C. Prépetit, and R. Momplaisir (2010), Transpressional rupture of an unmapped fault during the 2010 Haiti earthquake, Nat. Geosci., 3, 794-799.

Chen, P., L. Zhao, and T. H. Jordan (2007), Full 3D tomography for the crustal structure of the Los Angeles region, Bull. Seismol. Soc. Am., 97, 1094-1120.

Crosson, R. S. (1976), Crustal structure modeling of earthquake data 1. Simultaneous least squares estimation of hypocenter and velocity parameters, J. Geophys. Res., 81, 3036-3046, doi:10.1029/JB081i017p03036.

Day, S., Bielak, J., Dreger, D., Graves, R., Larsen, S., K. B. Olsen, Pitarka, A., and Ramirez-Guzman, L. (2006), Numerical simulation of basin effects on long-period ground motion, Proceedings of the 8th National Conference on Earthquake Engineering.

Douilly, R., et al. (2013), Crustal structure and fault geometry of the 2010 Haiti earthquake from temporary seismometer deployments, Bull. Seismol. Soc. Am., 103, 2305-2325.

Douilly, R., H. Aochi, E. Calais, and A. Freed (2015), Three-dimensional dynamic rupture simulations across interacting faults: The Mw7. 0, 2010, Haiti earthquake, J. Geophys. Res. Solid Earth, 120, 1108-1128, doi:10.1002/2014JB011595.

Eberhart-Phillips, D. (1986), Three-dimensional velocity structure in northern California Coast Ranges from inversion of local earthquake arrival times, Bull. Seismol. Soc. Am., 76, 1025-1052.

Eberhart-Phillips, D. (1993), Local earthquake tomography: Earthquake source regions, in Seismic Tomography: Theory and Practice, pp. 613-643, Chapman and Hall, London.

Eberhart-Phillips, D., and A. J. Michael (1998), Seismotectonics of the Loma Prieta, California, region determined from three-dimensional V P, V P/N S, and seismicity, J. Geophys. Res., 103, 21,099-21,120, doi:10.1029/98JB01984.

Eberhart-Phillips, D., and M. Reyners (1997), Continental subduction and three-dimensional crustal structure: The northern South Island, New Zealand, J. Geophys. Res., 102, 11,843-11,861, doi:10.1029/96JB03555.

Eberhart-Phillips, D., and Bannister, S. (2002), Three-dimensional crustal structure in the Southern Alps region of New Zealand from inversion of local earthquake and active source data, J. Geophys. Res., 107(B10), 2262, doi:10.1029/2001JB000567.

Evans, J. R., Eberhart-Phillips, D., and Thurber, C. (1994), User's manual for SIMULPS12 for imaging vp and vp/vs: A derivative of the "Thurber" tomographic inversion SIMUL3 for local earthquakes and explosions, US Geological Survey.

Fang, H., H. Yao, H. Zhang, Y.-C. Huang, and R. D. van der Hilst (2015), Direct inversion of surface wave dispersion for three-dimensional shallow crustal structure based on ray tracing: Methodology and application, Geophys. J. Int., 201, 1251-1263.

Fang, H., H. Zhang, H. Yao, A. Allam, D. Zigone, Y. Ben-Zion, C. Thurber, and R. D. van der Hilst (2016), A new algorithm for three-dimensional joint inversion of body wave and surface wave data and its application to the Southern California plate boundary region, J. Geophys. Res. Solid Earth, 121, 3557-3569, doi:10.1002/2015JB012702.

Foulger, G., and D. Toomey (1989), Tomographic inversion of local earthquake data from the Hengill-Grensdalur central volcano complex, Iceland, J. Geophys. Res., 94, 17-497, doi:10.1029/JB094iB12p17497. 
Goldstein, P., D. Dodge, M. Firpo, and L. Minner (2003), SAC2000: Signal processing and analysis tools for seismologists and engineers, in IASPEI International Handbook of Earthquake and Engineering Seismology, vol. 81, pp. 1613-1620, Academic Press, London.

Hardebeck, J. L. (2010), Seismotectonics and fault structure of the California Central Coast, Bull. Seismol. Soc. Am., 100, 1031-1050.

Haslinger, F., and E. Kissling (2001), Investigating effects of 3-D ray tracing methods in local earthquake tomography, Phys. Earth Planet. Inter., $123,103-114$.

Hauksson, E. (2000), Crustal structure and seismicity distribution adjacent to the Pacific and North American plate boundary in southern California, J. Geophys. Res., 105, 13,875-13,903, doi:10.1029/2000JB900016.

Hauksson, E., and J. S. Haase (1997), Three-dimensional V_P and V_P/V_S velocity models of the Los Angeles basin and central Transverse Ranges, California, J. Geophys. Res., 102, 5423-5453, doi:10.1029/96JB03219.

Kissling, E. (1988), Geotomography with local earthquake data, Rev. Geophys., 26, 659-698, doi:10.1029/RG026i004p00659.

Kissling, E., W. Ellsworth, D. Eberhart-Phillips, and U. Kradolfer (1994), Initial reference models in local earthquake tomography, J. Geophys. Res., 99, 19,635-19,646, doi:10.1029/93JB03138.

Kissling, E., U. Kradolfer, and H. Maurer (1995), Program VELEST USERS GUIDE-Short Introduction, Inst. Geophys. ETH Zurich, Zurich, Switz. Komatitsch, D., Q. Liu, J. Tromp, P. Süss, C. Stidham, and J. H. Shaw (2004), Simulations of ground motion in the Los Angeles basin based upon the spectral-element method, Bull. Seismol. Soc. Am., 94, 187-206.

Lees, J. M. (1990), Tomographic P-wave velocity images of the Loma Prieta earthquake asperity, Geophys. Res. Lett, 17, 1433-1436, doi:10.1029/GL017i009p01433.

Lees, J. M., and C. Nicholson (1993), Three-dimensional tomography of the 1992 southern California earthquake sequence: Constraints on dynamic earthquake rupture?, Geology, 21, 387-390.

Lees, J. M., and P. E. Malin (1990), Tomographic images of P wave velocity variation at Parkfield, California, J. Geophys. Res., 95, 21,793-21,804.

Lewis, M., Z. Peng, Y. Ben-Zion, and F. Vernon (2005), Shallow seismic trapping structure in the San Jacinto fault zone near Anza, California, Geophys. J. Int., 162, 867-881.

Lin, G., P. M. Shearer, E. Hauksson, and C. H. Thurber (2007), A three-dimensional crustal seismic velocity model for southern California from a composite event method, J. Geophys. Res., 112, B11306, doi:10.1029/2007JB004977.

Lin, G., C. H. Thurber, H. Zhang, E. Hauksson, P. M. Shearer, F. Waldhauser, T. M. Brocher, and J. Hardebeck (2010), A California statewide three-dimensional seismic velocity model from both absolute and differential times, Bull. Seismol. Soc. Am., 100, 225-240.

Magistrale, H., K. McLaughlin, and S. Day (1996), A geology-based 3D velocity model of the Los Angeles basin sediments, Bull. Seismol. Soc Am., 86, 1161-1166.

Manaker, D. M., E. Calais, A. Freed, S. Ali, P. Przybylski, G. Mattioli, P. Jansma, C. Prépetit, and J. De Chabalier (2008), Interseismic plate coupling and strain partitioning in the northeastern Caribbean, Geophys. J. Int., 174, 889-903.

McHugh, C. M., et al. (2011), Offshore sedimentary effects of the 12 January 2010 Haiti earthquake, Geology, 39, 723-726.

McNamara, D., et al. (2012), Frequency-dependent seismic attenuation within the Hispaniola Island region of the Caribbean Sea, Bull. Seismol. Soc. Am., 102, 773-782.

Meng, L., J.-P. Ampuero, A. Sladen, and H. Rendon (2012), High-resolution backprojection at regional distance: Application to the Haiti M7. 0 earthquake and comparisons with finite source studies, J. Geophys. Res., 117, B04313, doi:10.1029/2011JB008702.

Mercier de Lépinay, B., et al. (2011), The 2010 Haiti earthquake: A complex fault pattern constrained by seismologic and tectonic observations, Geophys. Res. Lett., 38, L22305, doi:10.1029/2011GL049799.

Michael, A. J., and D. Eberhart-Phillips (1991), Relations among fault behavior, subsurface geology, and three-dimensional velocity models, Science, 253, 651-654

Momplaisir, R. B.-A. (1986), Contribution a l'Etude Geologique de la partie orientale du massif de la hotte (presqu'ile de sud d'Haiti): synthese structurale des marges de la presqu'ile a partir de donnees sismiques, Ph.D. thesis, 210 pp. Univ. Pierre-et-Marie-Curie (Paris Vl), Paris.

Mooney, W. D., and A. Ginzburg (1986), Seismic measurements of the internal properties of fault zones, Pure Appl. Geophys., 124, 141-157.

Mori, J., D. J. Wald, and R. L. Wesson (1995), Overlapping fault planes of the 1971 San Fernando and 1994 Northridge, California earthquakes, Geophys. Res. Lett., 22, 1033-1036, doi:10.1029/95GL00712.

Nicholson, C., and J. M. Lees (1992), Travel-time tomography in the northern Coachella Valley using aftershocks of the 1986 ML 5.9 North Palm Springs Earthquake, Geophys. Res. Lett., 19, 1-4, doi:10.1029/91GL03037.

Olsen, K. B. (2000), Site amplification in the Los Angeles Basin from three-dimensional modeling of ground motion, Bull. Seismol. Soc. Am., 90, S77-S94.

Phillips, D. (1990), Three-dimensional P and S velocity structure in the Coalinga region, California, J. Geophys. Res., 95, 15,343-15,364, doi:10.1029/JB095iB10p15343.

Prentice, C., P. Mann, A. Crone, R. Gold, K. Hudnut, R. Briggs, R. Koehler, and P. Jean (2010), Seismic hazard of the Enriquillo-Plantain Garden fault in Haiti inferred from palaeoseismology, Nat. Geosci., 3, 789-793.

Pubellier, M., A. Mauffret, S. Leroy, J. M. Vila, and H. Amilcar (2000), Plate boundary readjustment in oblique convergence: Example of the Neogene of Hispaniola, Greater Antilles, Tectonics, 19, 630-648, doi:10.1029/2000TC900007.

Ryberg, T., and G. S. Fuis (1998), The San Gabriel Mountains bright reflective zone: Possible evidence of young mid-crustal thrust faulting in southern California, Tectonophysics, 286, 31-46.

Saint Fleur, N., N. Feuillet, R. Grandin, E. Jacques, J. Weil-Accardo, and Y. Klinger (2015), Seismotectonics of southern Haiti: A new faulting model for the 12 January 2010 M7. 0 earthquake, Geophys. Res. Lett, 42, 10,273-10,281, doi:10.1002/2015GL065505.

Scott, J. S., T. G. Masters, and F. L. Vernon (1994), 3-D velocity structure of the San Jacinto fault zone near Anza, California-I. P waves, Geophys. J. Int., 119, 611-626.

Shapiro, N. M., and M. Campillo (2004), Emergence of broadband Rayleigh waves from correlations of the ambient seismic noise, Geophys. Res. Lett., 31, L07614, doi:10.1029/2004GL019491.

Shapiro, N. M., M. Campillo, L. Stehly, and M. H. Ritzwoller (2005), High-resolution surface-wave tomography from ambient seismic noise, Science, 307, 1615-1618.

Shi, Z., and Y. Ben-Zion (2006), Dynamic rupture on a bimaterial interface governed by slip-weakening friction, Geophys. J. Int., 165, 469-484.

Spakman, W., S. van der Lee, and R. van der Hilst (1993), Travel-time tomography of the European-Mediterranean mantle down to $1400 \mathrm{~km}$ Phys. Earth Planet. Inter., 79, 3-74.

Symithe, S. J., E. Calais, J. S. Haase, A. M. Freed, and R. Douilly (2013), Coseismic slip distribution of the 2010 M 7.0 Haiti earthquake and resulting stress changes on regional faults, Bull. Seismol. Soc. Am., 103, 2326-2343.

Tape, C., Q. Liu, A. Maggi, and J. Tromp (2009), Adjoint tomography of the southern California crust, Science, 325, 988-992.

Thurber, C. (1993), Local earthquake tomography: Velocities and Vp/Ns-theory, in Seismic Tomography: Theory and Practice, pp. 563-583, Chapman and Hall, London. 
Thurber, C. H. (1983), Earthquake locations and three-dimensional crustal structure in the Coyote Lake area, central California, J. Geophys. Res., 88, 8226-8236, doi:10.1029/JB088iB10p08226.

Thurber, C. H., S. R. Atre, and D. Eberhart-Phillips (1995), Three-dimensional Vp and Vp/Vs structure at Loma Prieta, California, from local earthquake tomography, Geophys. Res. Lett., 22, 3079-3082, doi:10.1029/95GL03077.

Thurber, C., S. Roecker, W. Ellsworth, Y. Chen, W. Lutter, and R. Sessions (1997), Two-dimensional seismic image of the San Andreas Fault in the Northern Gabilan Range, central California: Evidence for fluids in the fault zone, Geophys. Res. Lett., 24, 1591-1594, doi:10.1029/ 97GL01435.

Wald, D. J., and R. W. Graves (1998), The seismic response of the Los Angeles basin, California, Bull. Seismol. Soc. Am., 88, $337-356$.

Wald, D. J., T. H. Heaton, and K. W. Hudnut (1996), The slip history of the 1994 Northridge, California, earthquake determined from strong-motion, teleseismic, GPS, and leveling data, Bull. Seismol. Soc. Am., 86, S49-S70.

Waldhauser, F., and W. L. Ellsworth (2000), A double-difference earthquake location algorithm: Method and application to the northern Hayward fault, California, Bull. Seismol. Soc. Am., 90, 1353-1368.

Wessel, P., and W. H. Smith (1998), New, improved version of generic mapping tools released, Eos Trans. AGU, 79(47), 579-579.

Yang, H., Z. Li, Z. Peng, Y. Ben-Zion, and F. Vernon (2014), Low-velocity zones along the San Jacinto Fault, Southern California, from body waves recorded in dense linear arrays, J. Geophys. Res. Solid Earth, 119, 8976-8990, doi:10.1002/2014JB011548.

Zhang, H., and C. H. Thurber (2003), Double-difference tomography: The method and its application to the Hayward fault, California, Bull. Seismol. Soc. Am., 93, 1875-1889.

Zhang, H., C. Thurber, and P. Bedrosian (2009), Joint inversion for vp, vs, and vp/vs at SAFOD, Parkfield, California, Geochem. Geophys. Geosyst., 10, Q11002, doi:10.1029/2009GC002709.

Zhao, D., and H. Kanamori (1995), The 1994 Northridge earthquake: 3-D crustal structure in the rupture zone and its relation to the aftershock locations and mechanisms, Geophys. Res. Lett., 22, 763-766, doi:10.1029/94GL03222. 